University of Nebraska - Lincoln

DigitalCommons@University of Nebraska - Lincoln

Publications, Agencies and Staff of the U.S.

Department of Commerce

U.S. Department of Commerce

2000

\title{
On Measuring Net Ecosystem Carbon Exchange over Tall Vegetation on Complex Terrain
}

\author{
Dennis Bladocchi \\ Ecosystem Science Division, Department of Environmental Science, Policy and Management,151 Hilgard \\ Hall, University of California, Berkeley, CA \\ John Finnigan \\ CSIRO Land and Water, GPO Box 821, Canberra, ACT 2601, Australia \\ Kell Wilson \\ Atmospheric Turbulence and Diffusion Division, NOAA, PO Box 2456, Oak Ridge, TN \\ K. T. Paw U \\ 4Department of Land, Air and Water Resources, University of California, Davis, CA \\ Eva Falge \\ Ecosystem Science Division, Department of Environmental Science, Policy and Management,151 Hilgard \\ Hall, University of California, Berkeley, CA
}

Follow this and additional works at: https://digitalcommons.unl.edu/usdeptcommercepub

Part of the Environmental Sciences Commons

Bladocchi, Dennis; Finnigan, John; Wilson, Kell; Paw U, K. T.; and Falge, Eva, "On Measuring Net Ecosystem Carbon Exchange over Tall Vegetation on Complex Terrain" (2000). Publications, Agencies and Staff of the U.S. Department of Commerce. 2.

https://digitalcommons.unl.edu/usdeptcommercepub/2

This Article is brought to you for free and open access by the U.S. Department of Commerce at DigitalCommons@University of Nebraska - Lincoln. It has been accepted for inclusion in Publications, Agencies and Staff of the U.S. Department of Commerce by an authorized administrator of DigitalCommons@University of Nebraska - Lincoln. 


\title{
ON MEASURING NET ECOSYSTEM CARBON EXCHANGE OVER TALL VEGETATION ON COMPLEX TERRAIN
}

\author{
DENNIS BALDOCCHI $^{1, \star}$, JOHN FINNIGAN ${ }^{2}$, KELL WILSON $^{3}$, K. T. PAW U ${ }^{4}$ and \\ EVA FALGE ${ }^{1}$ \\ ${ }^{1}$ Ecosystem Science Division, Department of Environmental Science, Policy and Management, 151 \\ Hilgard Hall, University of California, Berkeley, CA 94720, U.S.A.; ${ }^{2}$ CSIRO Land and Water, GPO \\ Box 821, Canberra, ACT 2601, Australia; ${ }^{3}$ Atmospheric Turbulence and Diffusion Division, NOAA, \\ PO Box 2456, Oak Ridge, TN 37831-2456, U.S.A.; ${ }^{4}$ Department of Land, Air and Water Resources, \\ University of California, Davis, CA 95616, U.S.A.
}

(Received in final form 11 October 1999)

\begin{abstract}
To assess annual budgets of $\mathrm{CO}_{2}$ exchange between the biosphere and atmosphere over representative ecosystems, long-term measurements must be made over ecosystems that do not exist on ideal terrain. How to interpret eddy covariance measurements correctly remains a major task. At present, net ecosystem $\mathrm{CO}_{2}$ exchange is assessed, by members of the micrometeorological community, as the sum of eddy covariance measurements and the storage of $\mathrm{CO}_{2}$ in the underlying air. This approach, however, seems unsatisfactory as numerous investigators are reporting that it may be causing nocturnal respiration flux densities to be underestimated.

A new theory was recently published by Lee (1998, Agricultural and Forest Meteorology 91: 3950) for assessing net ecosystem-atmosphere $\mathrm{CO}_{2}$ exchange $\left(N_{e}\right)$ over non-ideal terrain. It includes a vertical advection term. We apply this equation over a temperate broadleaved forest growing in undulating terrain. Inclusion of the vertical advection term yields hourly, daily and annual sums of net ecosystem $\mathrm{CO}_{2}$ exchange that are more ecologically correct during the growing season. During the winter dormant period, on the other hand, corrected $\mathrm{CO}_{2}$ flux density measurements of an actively respiring forest were near zero. This observation is unrealistic compared to chamber measurements and model calculations. Only during midday, when the atmosphere is well-mixed, do measurements of $N_{e}$ match estimates based on model calculations and chamber measurements. On an annual basis, sums of $N_{e}$ without the advection correction were $40 \%$ too large, as compared with computations derived from a validated and process-based model. With the inclusion of the advection correction term, we observe convergence between measured and calculated values of $N_{e}$ on hourly, daily and yearly time scales. We cannot, however, conclude that inclusion of a one-dimensional, vertical advection term into the continuity equation is sufficient for evaluating $\mathrm{CO}_{2}$ exchange over tall forests in complex terrain. There is an indication that the neglected term, $\bar{u}(\partial \bar{c} / \partial x)$, is non-zero and that $\mathrm{CO}_{2}$ may be leaking from the sides of the control volume during the winter. In this circumstance, forest floor $\mathrm{CO}_{2}$ efflux densities exceed effluxes measured above the canopy.
\end{abstract}

Keywords: AmeriFlux, FLUXNET, Carbon balance, Micrometeorology, Deciduous forest, Eddy covariance, Ecophysiology.

^E-mail: baldocchi@nature.berkeley.edu

Boundary-Layer Meteorology 96: 257-291, 2000.

Kluwer Academic Publishers. 


\section{Introduction}

Information on carbon dioxide fluxes between land and the atmosphere is needed to quantify and understand how the atmospheric composition of $\mathrm{CO}_{2}$ varies in time and in space. Knowing where terrestrial carbon sources and sinks are, how strong they may be, how they will respond to environmental perturbations and how they vary diurnally, seasonally and inter-annually are among the questions that remain unresolved within the carbon cycle research community (Heimann et al., 1986; Fan et al., 1998; Canadell et al., 2000).

Micrometeorological flux measurement methods have the potential for measuring, directly, the net flux density of carbon dioxide between patches of landscape and the atmosphere. The horizontal length scale of these measurements ranges from $100 \mathrm{~m}$ to several kilometres. Temporally, micrometeorological flux measurements can encompass time intervals ranging from hours to days through seasons and years.

The acquisition of measurement and $\mathrm{CO}_{2}$ flux data over extended periods is a relatively recent phenomenon. Until the work of Wofsy et al. (1993) and Vermetten et al. (1994), no one ventured to measure eddy fluxes of carbon dioxide over the course of a year. Yet, this is the relevant time scale for many ecosystem and biogeochemical cycling processes. In the meantime, a global network of long-term flux measurements sites, called FLUXNET, has been proposed (Baldocchi et al., 1996), and is now operating, with over 80 flux towers worldwide (http://www-eosdis.ornl.gov/FLUXNET). A majority of the sites are supported through the auspices of the EUROFLUX (Tenhunen et al., 1998; http://gaia.agraria.unitus.it/eflux/euro.html), AmeriFlux (Hollinger and Wofsy, 1997; http://cdiac.esd.ornl.gov/programs/ameriflux/) and MEDEFLU regional networks.

Early reports from the network tower sites are indicating that previously disturbed forests, growing in temperate zones, are taking up between 200 and $600 \mathrm{~g} \mathrm{C} \mathrm{m}^{-2}$ year $^{-1}$ from the atmosphere (Wofsy et al., 1993; Valentini et al., 1996; Greco and Baldocchi, 1996; Goulden et al., 1996a,b). Investigators working in boreal zones report relatively large rates of uptake for deciduous forests (Black et al., 1996), but small ecosystem carbon gains (Jarvis et al., 1997; Goulden et al., 1998) or losses (Lindroth et al., 1998) are being reported over conifer stands.

As long-term carbon dioxide flux data accumulate, the accuracy of some published sums of annual $\mathrm{CO}_{2}$ exchange are becoming subject to question for several fundamental reasons. First, native vegetation is seldom found in flat terrain. Consequently, many long-term flux measurement sites do not meet classical micrometeorological criteria that ensure the development of a constant flux layer (Kaimal and Finnigan, 1994; Foken and Wichura, 1995). The most severe sites are situated over tall forests in rolling terrain. Second, a cohort of carbon flux researchers suspect that they may be under-evaluating nighttime $\mathrm{CO}_{2}$ fluxes (Black et al., 1996; Lee et al., 1997; Goulden et al., 1996a,b; Baldocchi, 1997; Lavigne et 
al., 1997; Lindroth et al., 1998; Chen et al., 1999; Aubinet et al., 2000). Potential explanations include insufficient turbulent mixing, incorrect measurement of the storage term of $\mathrm{CO}_{2}$ in the air space and soil and the drainage of $\mathrm{CO}_{2}$ out of the canopy volume at night. All of these factors will cause a systematic bias of nighttime $\mathrm{CO}_{2}$ loss (see Moncrieff et al., 1996).

When integrated over 24 hours or on a yearly interval, this nocturnal bias error has the potential to amplify. A small night time bias error of $1 \mu \mathrm{mol} \mathrm{m}{ }^{-2} \mathrm{~s}^{-1}$, summed for 12-hour nights over one year, is equivalent to $189 \mathrm{~g} \mathrm{C} \mathrm{m}^{-2}$ year $^{-1}$. Errors of this magnitude can result in unrealistic annual sums that cannot be supported by independent biological measurements of tree and plant growth.

Numerous instrument, software, and model inter-comparison studies lead us to conclude that this nocturnal $\mathrm{CO}_{2}$ efflux measurement problem is associated with atmospheric conditions and the interpretation of eddy fluxes, rather than measurement errors. For example, nocturnal measurements of canopy respiration (using the same instruments and processing software) over short crops growing over flat terrain in windy environments do not underestimate model calculations of nocturnal respiration while those over tall forests do (Baldocchi and Meyers, 1998).

At present, several teams of investigators are applying an empirical correction to compensate for the underestimate of nighttime flux measurements. This correction is based on $\mathrm{CO}_{2}$ flux density measurements obtained during windy periods or by replacing data with a temperature-dependent respiration function (Lindroth et al., 1998; Black et al., 1996; Goulden et al., 1996a). Most researchers presume that data within windy periods represent conditions when the storage and drainage of $\mathrm{CO}_{2}$ is minimal (Aubinet et al., 2000).

Ideally, one would prefer to treat this problem on a physical basis rather than with an empirical correction. The regression correction, currently in vogue, suffers from autocorrelation. The standard deviation of vertical wind velocity fluctuations $\left(\sigma_{w}\right)$ is associated with the dependent (friction velocity, $\mathbf{u}_{*}$ ) and the independent variables $\left(\mathrm{CO}_{2}\right.$ flux density, $F_{c}=\overline{\rho_{a}} \overline{w \tilde{\mathrm{O}} c \tilde{\mathrm{O}}}=r_{w c} \sigma_{w} \sigma_{c} ; r_{w c}$ is the $w-\mathrm{CO}_{2}$ correlation coefficient and $\sigma_{c}$ is the standard deviation in $\mathrm{CO}_{2}$ mixing ratio). Most teams also report very low coefficients of determination $\left(r^{2}\right)$ between $F_{c}$ and $u_{*}$ (Aubinet et al., 2000). Rarely does $u_{*}$ explain more than $50 \%$ of the variance in $F_{c}$. Furthermore, there is no guarantee that empirical corrections developed at one site will be valid at another (Aubinet et al., 2000). For example, the need to correct nocturnal fluxes and the magnitude of this correction will differ if one's site is on convex topography, where air will drain away, or concave topography, where cold can air accumulate. For sites on ridges, the nocturnal build up of $\mathrm{CO}_{2}$ tends to be modest as some $\mathrm{CO}_{2}$ drains away. If some respired $\mathrm{CO}_{2}$ never reaches an eddy covariance measurement system, soil/root respiration will be underestimated if such drainage is not accounted for. For sites in concave topography, or bowls, nocturnal $\mathrm{CO}_{2}$ levels can become quite elevated as air drains into that region. The horizontal inflow of $\mathrm{CO}_{2}$ into a restricted volume will cause an eddy covariance measurement to overestimate the $\mathrm{CO}_{2}$ efflux from the underlying soil. 
At our site, near Oak Ridge, Tennessee in the U.S.A. we have been suspecting the accuracy of our nighttime $\mathrm{CO}_{2}$ flux density measurements during the dormant and growing seasons, when the thermal stratification of the atmosphere is stable and turbulent mixing is intermittent (Baldocchi, 1997). Several observations fuel this suspicion. During the winter when the forest is leafless, dormant and respiring, we often observe downward-directed eddy fluxes of carbon dioxide. This result is contrary to respiration measurements that have been made at our site with chambers. These data suggest a wintertime carbon dioxide efflux between 0.5 and $1 \mu \mathrm{mol} \mathrm{m}{ }^{-2} \mathrm{~s}^{-1}$ (Hanson et al., 1993; Chambers, 1998) that is constant over the course of a day. Spurious eddy flux observations occur most often when the weather is cold and during the night, early morning and early evening periods. On the other hand, better agreement between the direction and magnitude of micrometeorological and chamber derived fluxes occurs during midday when the planetary boundary layer is deep and turbulent mixing is robust. During the growing season, nighttime $\mathrm{CO}_{2}$ flux measurements significantly underestimate rates of canopy respiration derived from a model that computes accurate fluxes of photosynthesis and respiration during the day (Baldocchi, 1997; Baldocchi and Meyers, 1998). The consequence of these biases is significant. Simple sums of eddy covariance measurements yield a net annual carbon sink strength exceeding $900 \mathrm{~g} \mathrm{C} \mathrm{m}^{-2}$ year $^{-1}$. Fluxes of this magnitude are not defensible based on biometry measurements (Edwards et al., 1989; Paul Hanson, personal communication) and they exceed model calculations of annual net ecosystem carbon exchange by almost a factor of two.

If we are to produce defensible measurements of net annual carbon fluxes for the research community (e.g., Fan et al., 1998; Canadell et al., 2000), we must develop and implement a physically based theory that describes net exchange of material between the atmosphere and biosphere. Lee (1998) described a new method that accounts for the effect of advection on the evaluation of net atmosphere/biosphere trace gas exchange. In this paper, we evaluate Lee's theory by estimating daily and annual carbon fluxes over a 26-m tall temperate, deciduous, broadleaved forest growing in non-ideal terrain.

\section{Theory}

A client of mass and energy flux information wants to know how much material is being transferred across the land/air interface and what proportions of this material transfer are associated with the soil and with the vegetation. Atmospheric methods offer a way of accessing this 'net ecosystem exchange'. Such methods exploit the natural mixing of turbulent flow to sidestep the severe problems that spatial variability poses for other methods such as chambers or biomass sampling. Atmospheric methods, however, have their own limitations. It is prudent to be aware of them so that the proper confidence can be assigned to measurements in various situations. 
All atmospheric flux measurement approaches begin with the equation for the conservation of a scalar in air. For a point in space, the total time derivative for a change in scalar concentration with respect to time is composed of the local time derivative and the lateral advection of material through a conceptual cube. These terms are balanced by turbulent flux divergences across the faces of a conceptual cube and the amount of material that may be created or destroyed within the cube by biological and chemical processes,

$$
\begin{aligned}
\frac{\mathrm{d} \overline{\rho_{c}}}{\mathrm{~d} t} & =\overline{\rho_{a}} \frac{\mathrm{d} \bar{c}}{\mathrm{~d} t}=\overline{\rho_{a}}\left[\frac{\partial \bar{c}}{\partial t}+\overline{u_{i}} \frac{\partial \bar{c}}{\partial x_{i}}+\bar{c} \frac{\partial \overline{u_{i}}}{\partial x_{i}}\right] \\
& =-\overline{\rho_{a}} \frac{\partial \overline{u_{i}^{\prime} c^{\prime}}}{\partial x_{i}}+S_{B}\left(t, x_{i}\right)+S_{c h}\left(t, x_{i}\right) .
\end{aligned}
$$

Written in this form, $c$ is the mixing ratio of the scalar and $\rho_{a}$ is the mean density of dry air. Overbars denote ensemble or time averaged mean quantities and primes departures from the mean so that

$$
c=\bar{c}+c^{\prime}, \quad u_{i}=\overline{u_{i}}+u_{i}^{\prime} .
$$

Variables are expressed in a right-handed coordinate system $x_{i} \equiv x, y, z$ with corresponding velocity components $u_{i} \equiv u, v, w ; x_{1}$ (or $x$ ) is in the mean streamwise direction, $x_{3}$ (or $z$ ) in the vertical or surface normal direction and $x_{2}$ (or $y$ ) in the cross-stream, lateral direction. $S_{B}$ and $S_{c h}$ are the source strengths of $\bar{c}$ due to biology and chemical reactions respectively. Henceforth in this paper, we will ignore $S_{c h}$. A more formal derivation of Equation (1) would start with a budget equation of $\mathrm{CO}_{2}$ density $\left(\rho_{c}=\rho_{a} c\right.$, moles $\left.\mathrm{m}^{-3}\right)$ rather than mole fraction, which implicitly assumes that air density is constant. For more information on this topic, the reader is referred to the works of Webb et al. (1980) and Paw U et al. (2000).

For the simplest case, one assumes steady state conditions at a point, and horizontal homogeneity (no horizontal gradients). On this basis Equation (1) reduces to

$$
0=-\overline{\rho_{a}} \frac{\partial \overline{w^{\prime} c^{\prime}}}{\partial z}+S_{B}(z)
$$

In the layer between canopy top (height $h$ ) and the measurement height $\left(z_{r}\right)$ (a layer where $S_{B}(z)$ equals zero) Equation (2) reduces to the classical constant flux layer relationship, $\partial \overline{w^{\prime} c^{\prime}} / \partial z=0$.

Integrating Equation (2) from the ground to height $z_{r}$ yields an equation showing that the eddy covariance between vertical velocity and scalar concentration fluctuations equals the net flux of material in and out of the underlying soil and vegetation, as delimited by the canopy height, $h$

$$
\rho_{a} \overline{w^{\prime} c^{\prime}\left(z_{r}\right)}=\rho_{a} \overline{w^{\prime} c^{\prime}(0)}+\int_{0}^{h} S_{B}(z) \mathrm{d} z .
$$


For the case of $\mathrm{CO}_{2}$ exchange, this relation presumes to measure net ecosystematmosphere exchange of $\mathrm{CO}_{2}\left(N_{e}\right)$, the balance between photosynthesis and autotrophic and heterotrophic respiration. The equation is derived from the perspective of the atmosphere, so positive flux densities are directed upward towards the atmosphere and negative ones are directed downward towards the ecosystem. We have written $\overline{w^{\prime} c^{\prime}}(0)$ as shorthand for the flux density of $c$ at the soil surface. This efflux represents soil-root respiration. We ignore complications caused by the local spatial variation of quantities in the plant-air space, which requires us to volume average quantities to obtain meaningful within-canopy variables.

To use any of these equations in practice we must make the ergodic assumption. In other words, we replace the ensemble average by a time average taken over some period $T$. We desire a value of $T$ that is much longer than the period of any turbulent motion that contributes to the eddy flux at the measurement height. Unfortunately, this is not always possible and puts an unavoidable upper limit on the accuracy with which we can close budgets like Equation (1) (Kaimal and Finnigan, 1994). We shall now consider the consequences of relaxing these restrictions to a degree that reflects the reality of our experimental situation.

When the thermal stratification of the atmosphere is stable or turbulent mixing is weak, material diffusing from leaves and the soil may not reach the reference height $z_{r}$ in a time that is small compared to the averaging time $T$, thereby violating the assumption of steady state. Under such conditions the storage term becomes nonzero, so it must be added to the eddy covariance measurement to balance material flowing into and out of the soil and vegetation,

$$
\overline{\rho_{a}} \overline{w^{\prime} c^{\prime}\left(z_{r}\right)}+\overline{\rho_{a}} \int_{0}^{z_{r}} \frac{\partial \bar{c}}{\partial t} \mathrm{~d} z=\overline{\rho_{a}} \overline{w^{\prime} c^{\prime}(0)}+\int_{0}^{h} S_{B}(z) \mathrm{d} z .
$$

While the storage term is small over short crops, it is an important quantity over taller forests. With respect to $\mathrm{CO}_{2}$, the storage term value is greatest around sunrise and sunset when there is a transition between respiration and photosynthesis and between the stable nocturnal boundary layer and daytime convective turbulence (Goulden et al., 1996b). We also note that Equation (4) provides the theoretical framework that is being used by a majority of the FLUXNET community (Aubinet et al., 2000; Wofsy et al., 1993; Black et al., 1996; Greco and Baldocchi, 1996).

Advection of mass and energy can occur in circumstances when the underlying surface is heterogeneous. The most prominent situation involves flow across the border of surfaces with different roughness or different source/sink strengths. Examples of cases where advection of mass and energy is notable include transitions between forests and crops, vegetation and lakes, desert and irrigated crops (Rao et al., 1974; Bink, 1996; Sun et al., 1997). The advection of mass and energy is also ubiquitous in complex terrain, where drainage flows can occur (Kaimal and Finnigan, 1994; Raupach and Finnigan, 1997). Pioneering micrometeorological studies by Mordukhovich and Tsvang (1966), for instance, showed that sloping terrain causes horizontal homogeneities and flux divergence. We stress that the 
constant flux layer fails to exist when advection occurs (see Rao et al., 1974; Bink, 1996; Raupach and Finnigan, 1997). So flux covariance measurements made at a single point are invalid measures of the biological activity of the underlying canopy.

An equation defining the conservation budget in two dimensions (where the $\mathrm{x}$ axis is aligned along the mean wind direction) introduces additional terms,

$$
\begin{aligned}
\overline{\rho_{a}} & {\left[\frac{\partial \bar{c}}{\partial t}+\bar{u} \frac{\partial \bar{c}}{\partial x}+\bar{w} \frac{\partial \bar{c}}{\partial z}+\bar{c} \frac{\partial \bar{u}}{\partial x}+\bar{c} \frac{\partial \bar{w}}{\partial z}\right] } \\
=-\overline{\rho_{a}} & {\left[\frac{\partial \overline{u^{\prime} c^{\prime}}}{\partial x}+\frac{\partial \overline{w^{\prime} c^{\prime}}}{\partial z}\right]+S_{B}(x, z, t) . }
\end{aligned}
$$

Equation (5) is an expression of the conservation of mass at a point. To make practical use of Equation (5) one should integrate it over a control volume whose lower boundary consists of the interface between the air and the soil, under the vegetation, and whose upper and lateral boundaries are fixed in the air.

Motivated by a need to circumvent this complexity, Lee (1998) re-visited the budget equation (Equation (1)) and applied it to the case of $\mathrm{CO}_{2}$ exchange. His goal was to derive an equation that could be used to assess fluxes under nonideal conditions using conventional experimental instrumentation, mounted on a solitary tower. To do so, he assumed advection was non-negligible in the vertical and longitudinal directions.

The convergence and divergence of streamlines, as wind flows over hills, will cause individual terms associated with $\bar{c}\left(\partial \overline{u_{i}} / \partial x_{i}\right)$ to be non-zero (Kaimal and Finnigan, 1994). Lee (1998) invoked the continuity equation $(\partial \bar{u} / \partial x+\partial \bar{w} / \partial z=0)$ to evaluate the horizontal gradient for $\bar{u}$ in terms of the vertical gradient of $\bar{w}$,

$$
\frac{\partial \bar{u}}{\partial x}=-\frac{\partial \bar{w}}{\partial z} \approx-\frac{\overline{w_{r}}}{z_{r}} .
$$

The term, $\overline{w_{r}}$, is defined as a mean vertical velocity measured at the reference height, $z_{r}$. This mean vertical velocity should not be confused with the raw vertical velocity output of a sonic anemometer. On flat terrain, non-zero values of $\overline{w_{r}}$ occur on the time scale of hours. Such non-zero values arises from convection, synoptic scale subsidence or local circulating flows due to thermal effects (Lee, 1998). Over complex terrain, drainage flows will cause $\overline{w_{r}}$ to be non-zero, too.

The other assumptions made by Lee (1998) include

$$
\begin{gathered}
\frac{\partial \overline{u^{\prime} c^{\prime}}}{\partial x}=0, \\
\bar{u} \frac{\partial \bar{c}}{\partial x}=0,
\end{gathered}
$$




$$
\bar{w} \frac{\partial \bar{c}}{\partial z}+\bar{c} \frac{\partial \bar{w}}{\partial z}=\frac{\partial \overline{w c}}{\partial z} .
$$

Following the assumptions made by Lee (1998), an expression for net ecosystem exchange of $\mathrm{CO}_{2},\left(N_{e}\right)$, the flux density of $\mathrm{CO}_{2}$ exchange between the biosphere and atmosphere, is derived. It equals the sum of the eddy covariance, measured at a reference height, the storage term and a parameterized 'advection' term,

$$
\begin{aligned}
N_{e} & =\overline{\rho_{a}} \overline{w^{\prime} c^{\prime}(0)}+\int_{0}^{h} S_{b}(z, t) \mathrm{d} z \\
& =\overline{\rho_{a}}\left[\overline{w^{\prime} c^{\prime}\left(z_{r}\right)}+\int_{0}^{z_{r}} \frac{\partial \bar{c}}{\partial t} \mathrm{~d} z+\int_{0}^{z_{r}} \bar{w} \frac{\partial \bar{c}}{\partial z} \mathrm{~d} z\right] .
\end{aligned}
$$

Assessing the terms on the right-hand side of Equation (10) yields

$$
N_{e}=\overline{\rho_{a}}\left[\overline{w^{\prime} c^{\prime}\left(z_{r}\right)}+\int_{0}^{z_{r}} \frac{\partial \bar{c}}{\partial t} \mathrm{~d} z+\overline{w_{r}}\left(\overline{c_{r}}-\langle c\rangle\right)\right]
$$

where

$$
\overline{w_{r}}=\bar{w}\left(z_{r}\right) \quad \text { and } \quad\langle c\rangle=\frac{1}{z_{r}} \int_{0}^{z_{r}} \bar{c}(z) \mathrm{d} z .
$$

The mean, vertical velocity at the reference height $\left(\overline{w_{r}}\right)$ is the difference between two other vertical velocities,

$$
\overline{w_{r}}=\bar{w}-\hat{w} .
$$

The vertical velocity, denoted $\bar{w}$, is the temporally averaged, vertical velocity, which is measured over a 30-minute interval with a sonic anemometer. The other vertical velocity $(\hat{w})$ is a function of wind direction (hence, topography) and instrument orientation and bias offsets attributed to the tower and anemometer (Figure 1).

Normalized vertical bias velocity $(\hat{w})$ is a quasi-sinusoidal function of wind direction. In principle this behaviour results because vertical velocity is positive when air flows up the hill, it is negative when it flows down the slope and is zero when wind is aligned across the slope (Rannik, 1998). At this complex site, the majority of data come from the southwest and northeast quadrants. From these quadrants the rotation angle is typically less than 10 degrees, which is not too severe to cause flow separation and to shed wake vortices. The other feature to be noted in Figure 1 is how the data scatter along the regression line. This scatter denotes the functional behaviour of $w_{r}$. These deviations are presumed to be due to drainage flow or localized convection (Avissar and Pielke, 1989; Lee, 1998). 


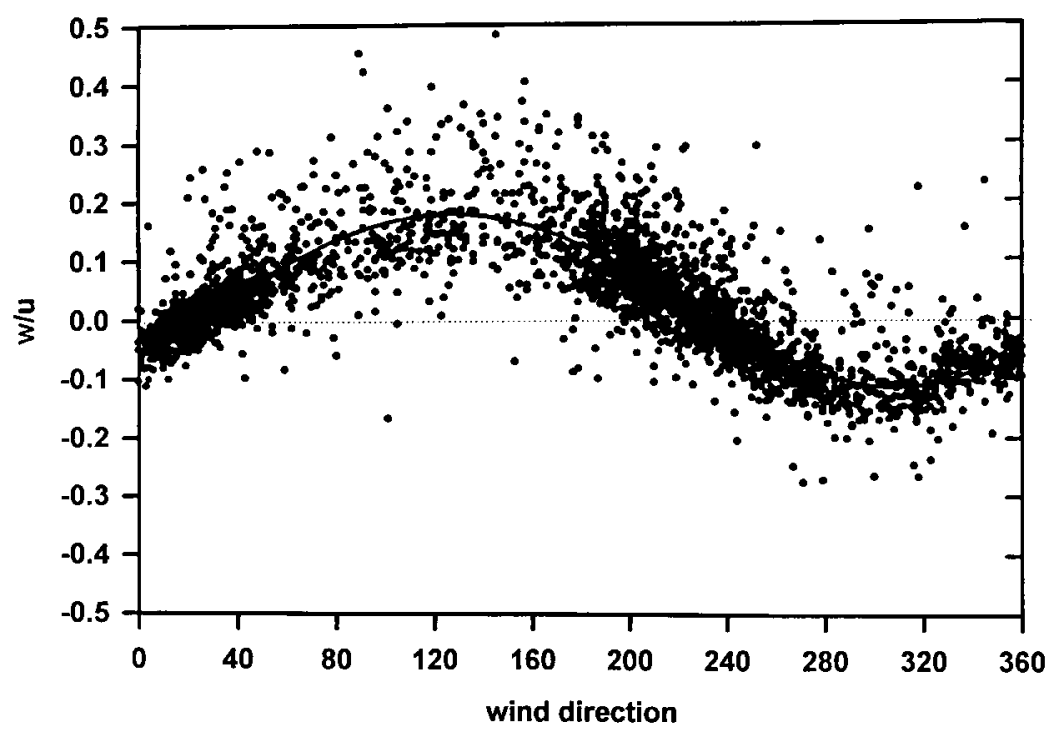

Figure 1. The relation between the ratio of vertical $(\bar{w})$ to horizontal wind speed $(U)$ and wind direction. These data were obtained over a temperate broadleaved forest, growing on rolling terrain. The data were obtained during the period between days 171 and 253, 1998.

Ideally, we wish to rotate the coordinate system of the sonic anemometer so that the mean wind velocity is oriented along with the mean streamline flowing over the landscape. In this new coordinate system flux covariances are orthogonal to the mean streamlines. Over level terrain and in the absence of mesoscale circulations, this condition is attained naturally, as mean vertical velocities equal zero and are independent of wind direction. Over rolling terrain or under conditions where mesoscale circulations persist, this ideal behaviour is not expected or observed.

Coordinate rotation of scalar-velocity covariances were performed by mathematically rotating $\hat{w}$ and $\bar{v}$ to zero (rather than rotating $\bar{w}$ to zero, which has been done in the past) (Wesely, 1970; Baldocchi et al., 1988). In practice, we found that rotating $\hat{w}$ to zero, rather than rotating $\bar{w}$ to zero, may be academic. Calculations showed that it had little impact on our eddy covariance calculations. Rotating $\bar{w}$ to zero, rather than $\hat{w}$, reduced $\overline{w^{\prime} c^{\prime}}$ by only $4 \%, \overline{w^{\prime} T^{\prime}}$ by $2.8 \%$ and $\overline{w^{\prime} q^{\prime}}$ by less than $1 \%$.

\section{Materials and Methods}

\subsection{Site CHARACTERISTICS}

The experimental field site is located on the United States Department of Energy reservation near Oak Ridge, Tennessee $\left(35^{\circ} 57^{\prime} 30^{\prime \prime} \mathrm{N} ; 84^{\circ} 17^{\prime} 15^{\prime \prime} \mathrm{W} ; 335 \mathrm{~m}\right.$ above mean sea level). A topographical map of the site is presented in Figure 2. The met- 


\section{Walker Branch Watershed, Oak Ridge, TN}

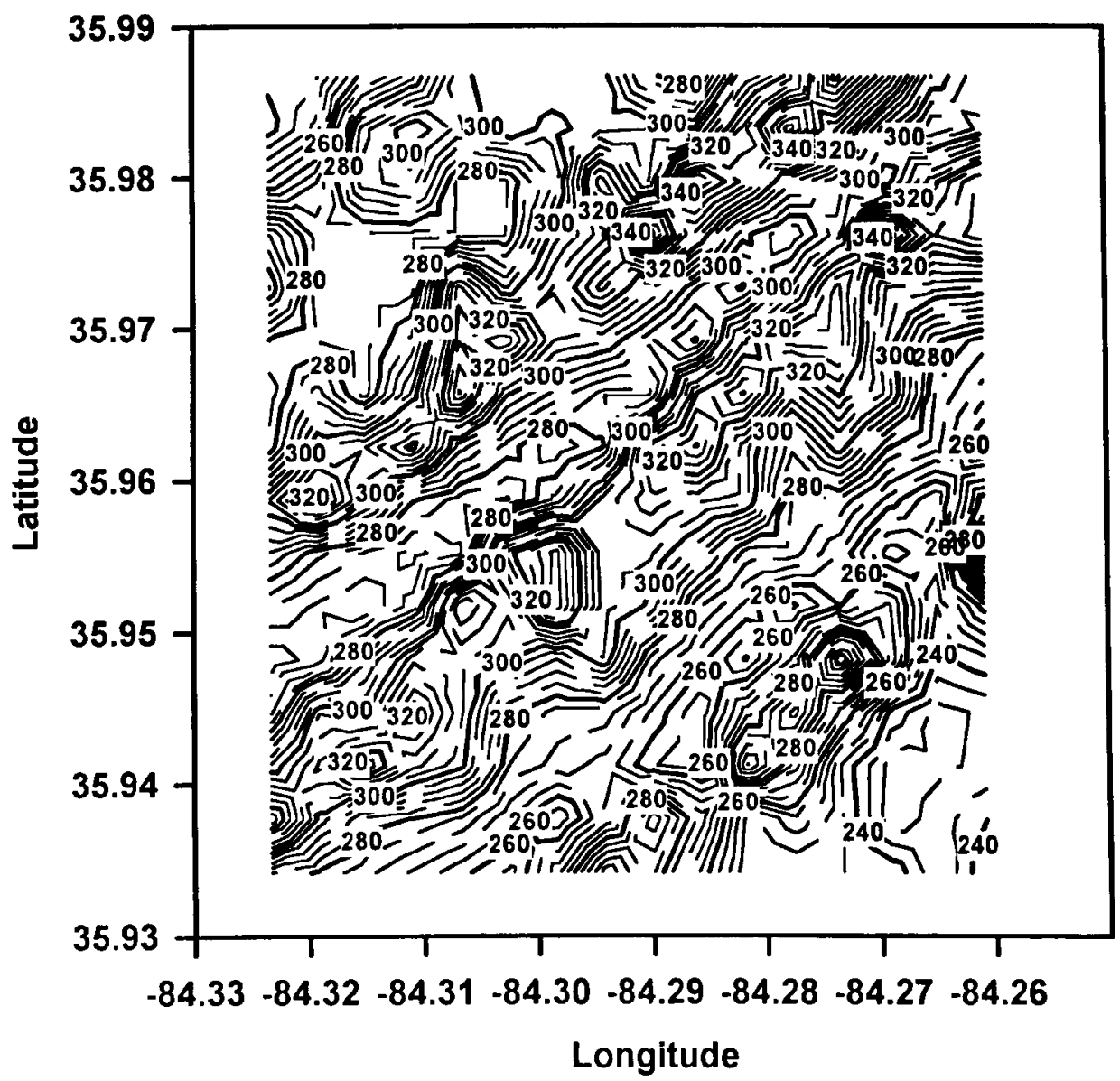

Figure 2. A topographic map of the Walker Branch Watershed field site, near Oak Ridge, TN. The data were obtained from the U.S. Geological Survey's worldwide web site, http://edcwww.cr.usgs.gov/glis/hyper/guide.

eorological tower is on a spur ridge, which slopes about $3 \%$ to the west-southwest, a direction from which the wind predominantly flows (see Figure 3). The vertical difference between ridge valley altitude within a two kilometre radius of the tower is on the order of sixty metres.

Vegetation at the site consists of mixed-species, broad-leaved forest, growing in the eastern North American deciduous forest biome. The predominant species in the forest stand are oak (Quercus alba L., Q. prinus L.), hickory (Carya ovata (Mill.) K. Koch), maple (Acer rubrum L.), tulip poplar (Liriodendron tulipifera L.) and loblolly pine (Pinus taeda L.). The forest has been growing since agricultural 


\section{wind direction frequency wind speed $\left(\mathrm{m} \mathrm{s}^{-1}\right)$}

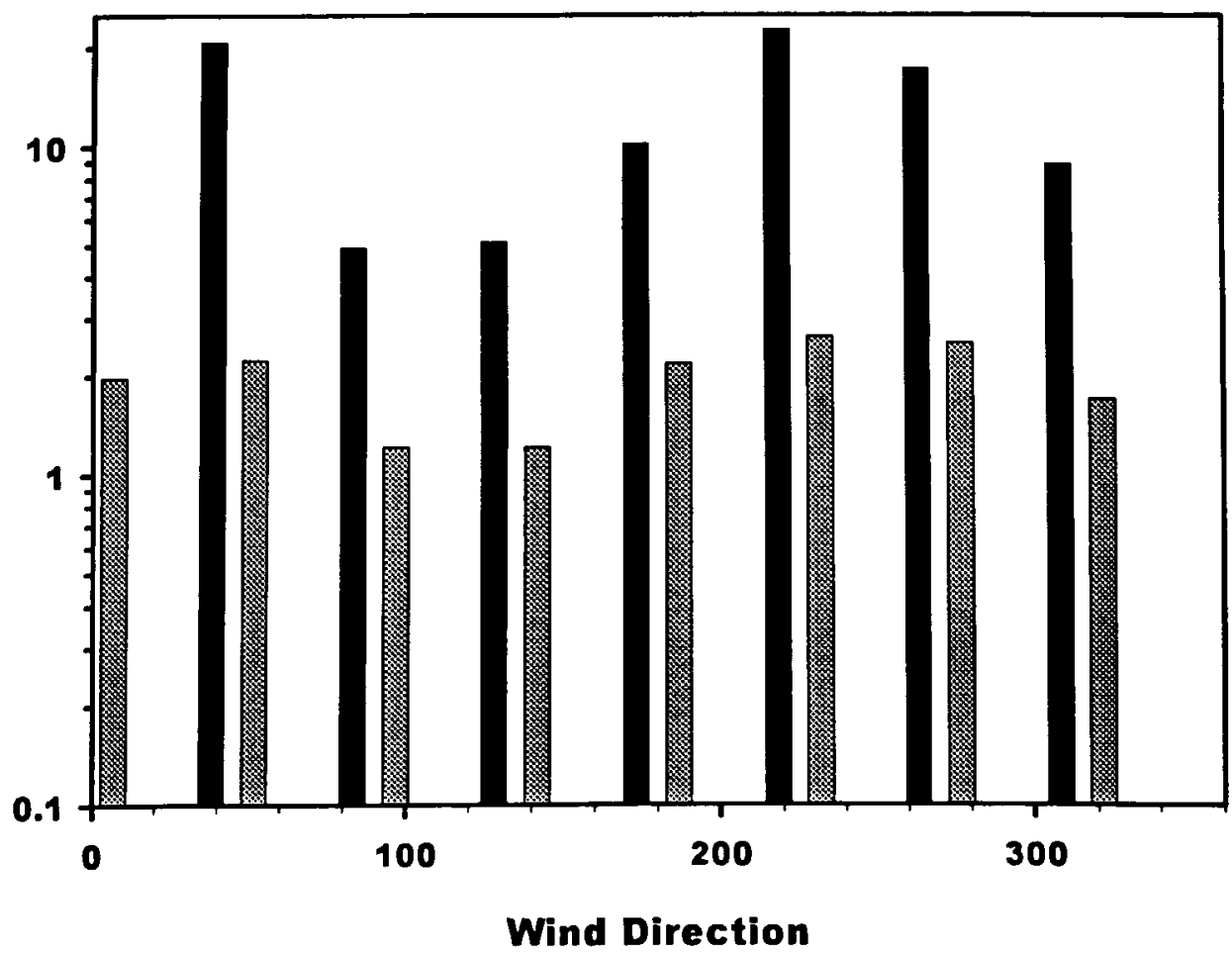

Figure 3. Histogram of wind frequency and wind velocity $\left(\mathrm{m} \mathrm{s}^{-1}\right)$ according to wind direction class. The data were obtained during 1997 over a broadleaved forest near Oak Ridge, TN.

abandonment in 1940. The mean canopy height was about $26 \mathrm{~m}$. The peak leaf area index of the canopy typically occurs by day 140 and reaches about 6.0. Leaf nitrogen content is about $1.8 \%$. The soil is classified as a Fullerton series, Typic Paleudult, otherwise described as an infertile cherty silt-loam. Additional details on the site are reported in Hutchison and Baldocchi (1989).

\subsection{MeAsurements, instrumentation And CALCUlations}

A set of micrometeorological instruments was supported $36.9 \mathrm{~m}$ above the ground (10 $\mathrm{m}$ over the forest) on a walk-up scaffold tower. Wind velocity and virtual temperature fluctuations were measured with a three-dimensional sonic anemometer (model SWS-211/3K, Applied Technology, Boulder, CO). Carbon dioxide and water vapour fluctuations were measured with an open-path, infrared absorption gas analyzer (Auble and Meyers, 1992). A second set of flux measurement instrumentation, identical to the types used at $36 \mathrm{~m}$, was implemented $2 \mathrm{~m}$ above 
the forest floor, to obtain an estimate of forest floor respiration (see Baldocchi and Meyers, 1991).

Micrometeorological data were sampled and digitized ten times per second. Inhouse software was used to process the measurements. The software computed covariances between velocity and scalar fluctuations over half-hour intervals. Turbulent fluctuations were calculated from the difference between instantaneous and mean quantities. Mean velocity and scalar values were determined, in real-time, using a digital recursive filter. The digital filter algorithm employed a $400 \mathrm{~s}$ time constant. Extensive tests have shown that flux covariances computed with this time constant yield values that agree within $2 \%$ of covariances computed with conventional Reynolds' averaging (also see McMillen, 1988).

The fast response $\mathrm{CO}_{2}$ /water vapour sensor was calibrated against gas standards. The calibration standards for $\mathrm{CO}_{2}$ were traceable to those prepared by NOAA's Climate Monitoring and Diagnostic Laboratory. The output of the water vapour channel was referenced to a dew point hygrometer. Corrections for density fluctuations to $\mathrm{CO}_{2}$ and water vapour fluctuations were applied to the scalar covariances that were measured with the open path sensor (Webb et al., 1980; Paw U et al., 2000).

The $\mathrm{CO}_{2}$ storage term was estimated, by finite difference, with a $\mathrm{CO}_{2}$ profile measurement system. An automatically-controlled, solenoid sampling system directed air into an infrared gas analyzer (model LI 6262, LiCor Inc., Lincoln, Nebraska). Air was sampled from four levels above and within the forest $(36,18$, $10,0.75 \mathrm{~m}$ ). Air from each level flowed through the analyzer for 30 seconds and data were sampled during the last 20 seconds of sampling. This scheme allowed a direct measurement of the profile every $120 \mathrm{~s}$. The gas measurement system was automatically calibrated each day at midnight by passing gases of known concentration through the analyzer.

The CANOAK model was used to diagnose and interpret the field measurements with an ecophysiological perspective. The CANOAK model is a processbased and coupled micrometeorological and ecophysiological model, for computing the canopy microclimate and mass and energy exchange between the forest and the atmosphere. The model has been thoroughly tested and described elsewhere (Baldocchi, 1997; Baldocchi and Meyers, 1998).

\section{Results}

Hour by hour measurements of canopy/atmosphere $\mathrm{CO}_{2}$ exchange over the course of a year (1997) are presented in Figure 4. These data were evaluated as the covariance between vertical velocity and $\mathrm{CO}_{2}$ mole density (Equation (3)). Figure 4 documents why we have been suspecting the interpretation of $\mathrm{CO}_{2}$ flux densities at our topographically-challenged forest site, as measured with the classical eddy covariance method. Numerous measurements of 'net photosynthesis' were recor- 
ded (before day 100 and after day 300) when the forest was dormant, leafless, and respiring. Despite the nonsensical direction of net ecosystem carbon exchange during the winter, many of these eddy covariance measurements may have been accurate. From a statistical sampling perspective, positive and negative values must be recorded when the net flux is near zero, as is expected when the soil and air are cold and below freezing point.

Observations obtained during the growing season (days 100 to 300) provide another reason for suspecting classical eddy covariance measurements. A majority of nighttime measurements of $\mathrm{CO}_{2}$ exchange were lower during the growing season than winter-time respiration rates, when temperature was over $10^{\circ} \mathrm{C}$ lower.

If we evaluate net ecosystem $\mathrm{CO}_{2}$ exchange, in terms of Equation (4), the sum of the eddy covariance and storage terms, we observe greater values of nocturnal respiration during the summertime (Figure 5). However, many periods with downward directed fluxes, during the dormant period, remain in the data set. At this point we address whether the addition of the advection correction term, advocated by Lee (1998), can remedy our results.

The advective mass flux density term (the third term on the right-hand side of Equation (11)) is the product, $\overline{w_{r}}\left(\overline{c_{r}}-\langle c\rangle\right)$. The seasonal variation is shown in Figure 6. The majority of values are confined within $\pm 20 \mu \mathrm{mol} \mathrm{m}^{-2} \mathrm{~s}^{-1}$. The breadth of the data scatter, however, varies with season. The peak-to-peak variation is rather narrow during the dormant period when $\mathrm{CO}_{2}$ gradients are weak and the variation is broad in the summer, when the vertical $\mathrm{CO}_{2}$ gradient is strong.

In contrast, no seasonality in the hourly variation of $w_{r}$ is observed (Figure 7). The values of the non-local vertical velocity $\left(w_{r}\right)$ are symmetric about zero and most of the values are confined within the range of $\pm 0.25 \mathrm{~m} \mathrm{~s}^{-1}$. Over the course of the year, $w_{r}$ sums to nearly zero.

The seasonal pattern of net ecosystem $\mathrm{CO}_{2}$ exchange $\left(N_{e}\right)$, as evaluated with Equation (11), is shown in Figure 8. More substantial rates of nocturnal respiration are estimated during the growing season, with the application of this equation. On the other hand, the data scatter is enhanced during the dormant period, due to an additional source of experimental measurement error (the $\mathrm{CO}_{2}$ concencentration gradient and the vertical drift velocity). And, we have not eliminated the downward directed fluxes of carbon over the dormant forest stand. In the following discussion, we dissect the information in Figure 8 to better understand when Equation (11) may or may not increase the accuracy of net ecosystem carbon exchange.

The mean diurnal pattern of bin-averaged measurements of $N_{e}$ during the growing season is presented in Figure 9 for $N_{e}$ (Equation (11)). Also shown in the figure are the mean diurnal courses of the eddy flux covariance $\left(F_{w p l}\right.$, Equation (3)), the eddy covariance plus the storage term (Equation (4)) and a computation of $N_{e}$ that was derived from the CANOAK model (Baldocchi, 1997). Simply measuring $N_{e}$ as a function of the eddy covariance $\left(\overline{w^{\prime} c^{\prime}}\right)$ yields a metric that does not detect reasonable and expected rates of nocturnal respiration, as based on model calculations. Adding the carbon flux attributed to the $\mathrm{CO}_{2}$ storage term does not 


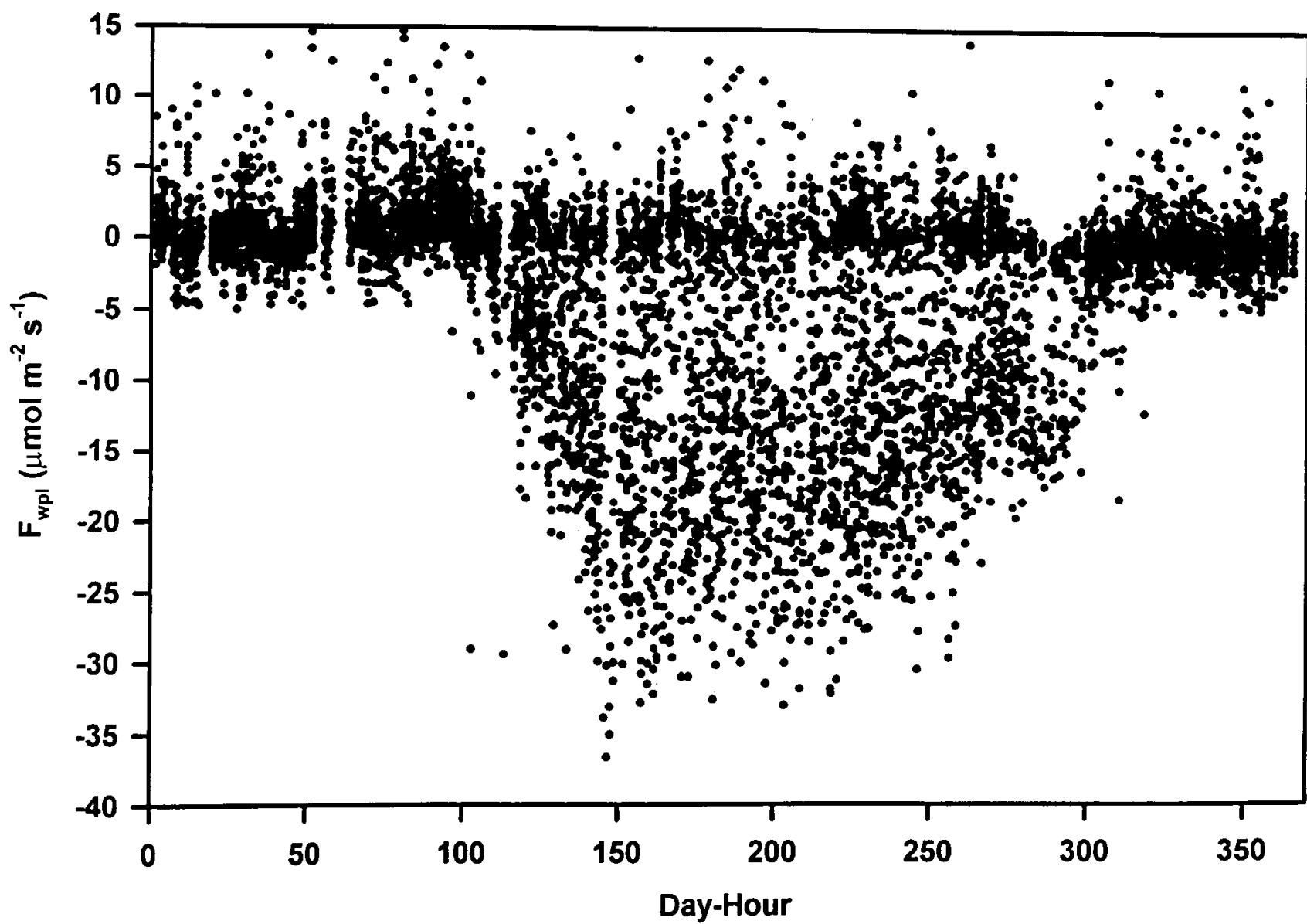

Figure 4. The seasonal pattern of net canopy $\mathrm{CO}_{2}$ exchange, as computed with the eddy covariance relationship, Equation (3). These data were obtained over a temperate broadleaved forest during 1997. 


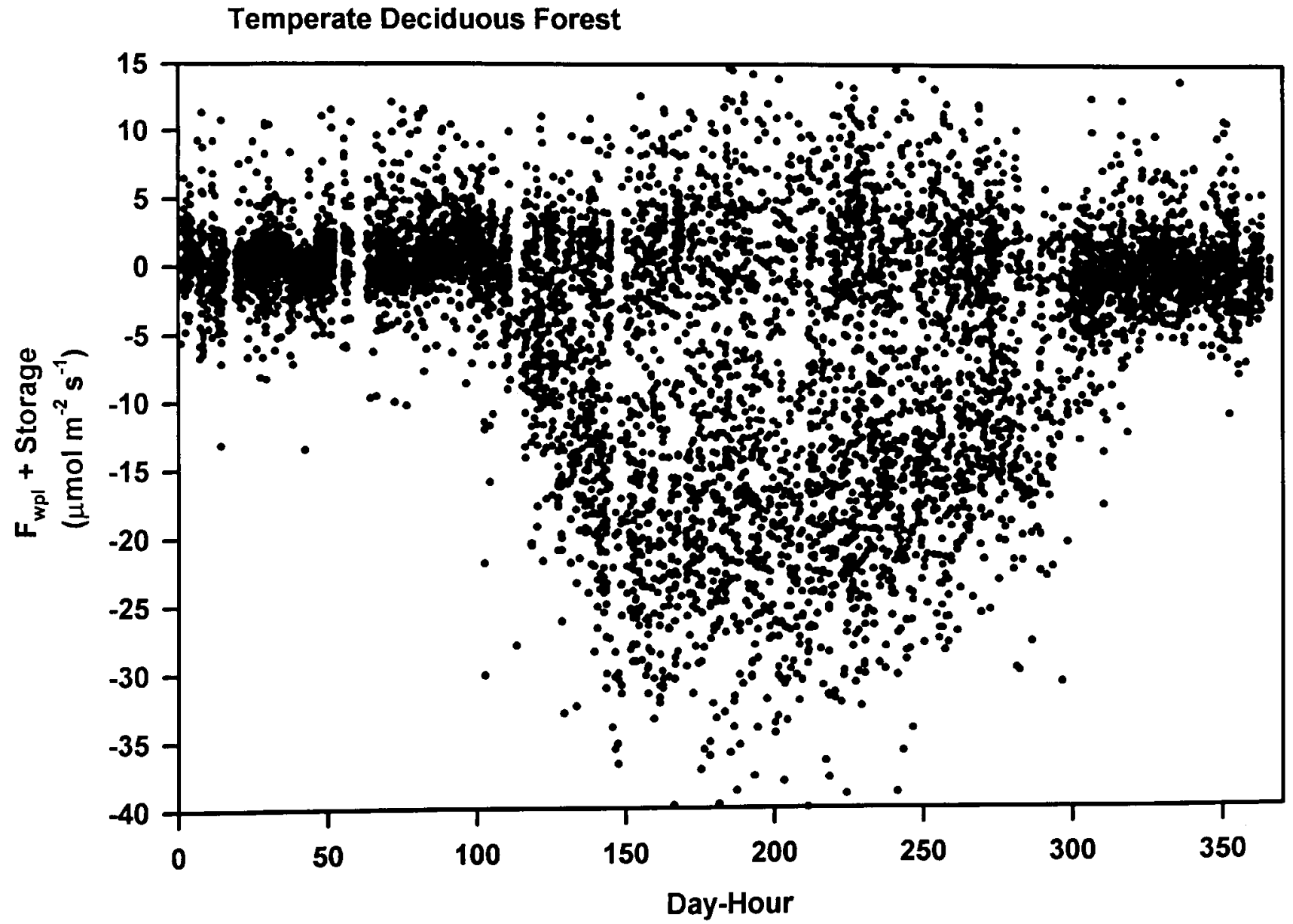




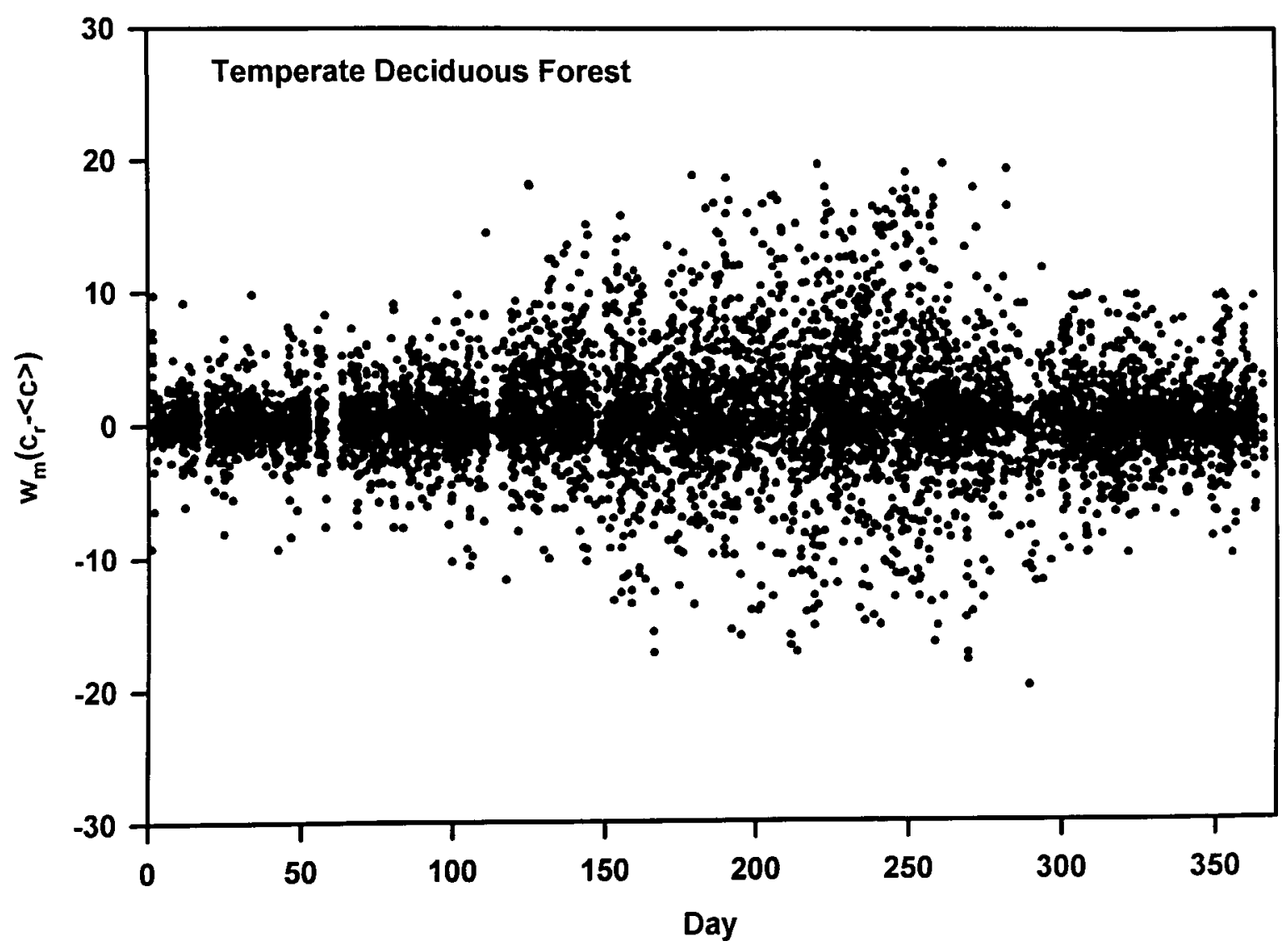




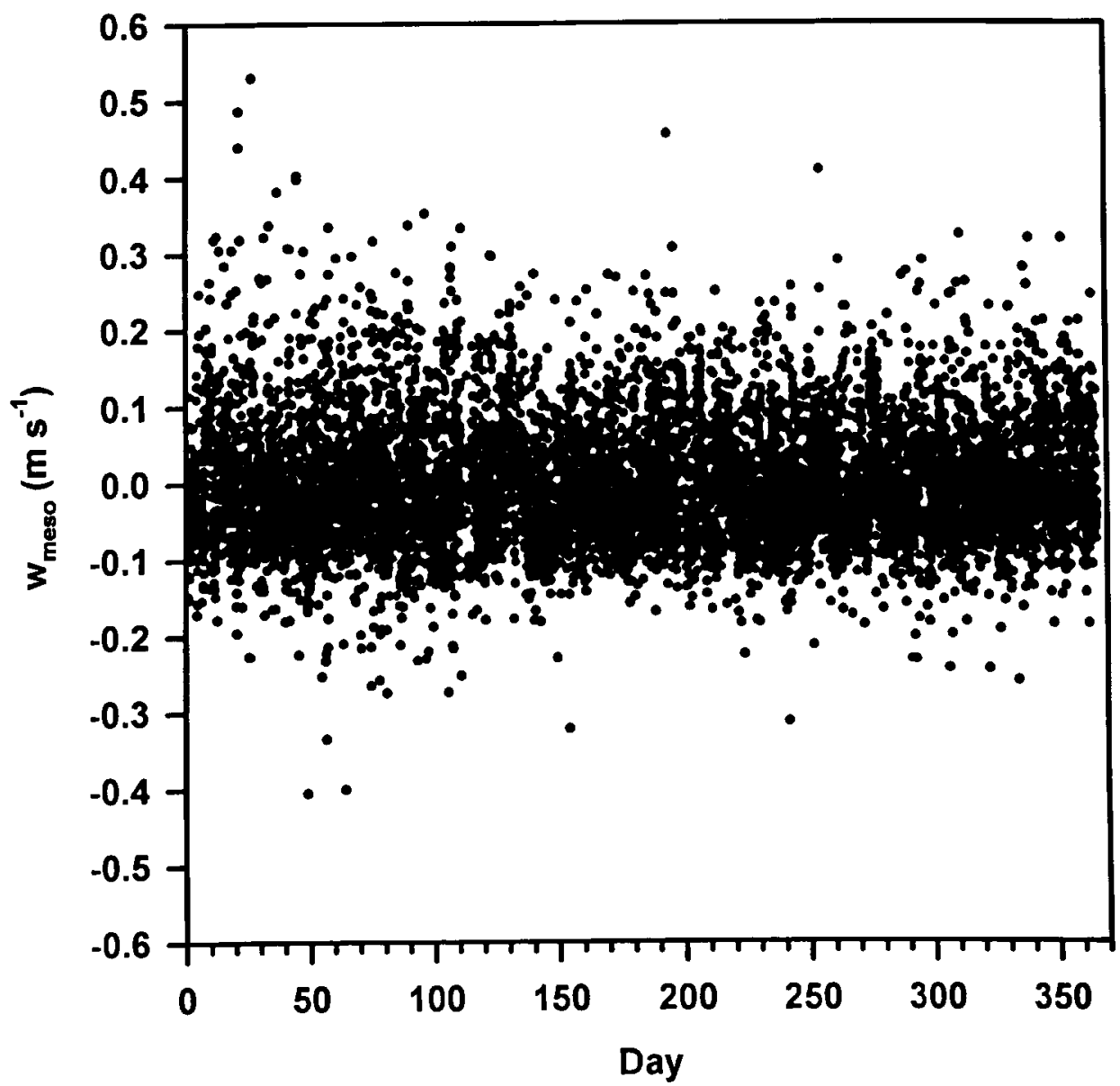

Figure 7. The hourly variation in values of the vertical drift velocity $\left(\overline{w_{r}}\right)$ over the course of a year.

bring canopy respiration into agreement with model calculations either (measured: -5.96 vs computed: $-5.09 \mathrm{~g} \mathrm{C} \mathrm{m}^{-2}$ day $^{-1}$ ). Inclusion of the storage flux term only adds $0.12 \mathrm{~g} \mathrm{C} \mathrm{m}^{-2}$ day $^{-1}$ to the total flux. Treating all terms associated with eddy covariance, storage and advection, however, produces estimates of nocturnal respiration that match model calculations with reasonable fidelity, within 5\% (-4.84 and $-5.09 \mathrm{~g} \mathrm{C} \mathrm{m}^{-2}$ day $^{-1}$, respectively).

Though our logic may seem reversed by testing a measurement theory with a model, it seems justified, in this case. First, the low accuracy of near-zero nocturnal eddy covariance measurements, based on Equation (4), is well known (Lee, 1998; Lavigne et al., 1997), so it is not a reliable standard. Second, we are confident about the performance of the model calculations because past tests show the model agrees well with daytime $\mathrm{CO}_{2}$, the sum of photosynthesis and respiration (Baldocchi, 1997). Accurate estimates of daytime respiration should be an indicator of 


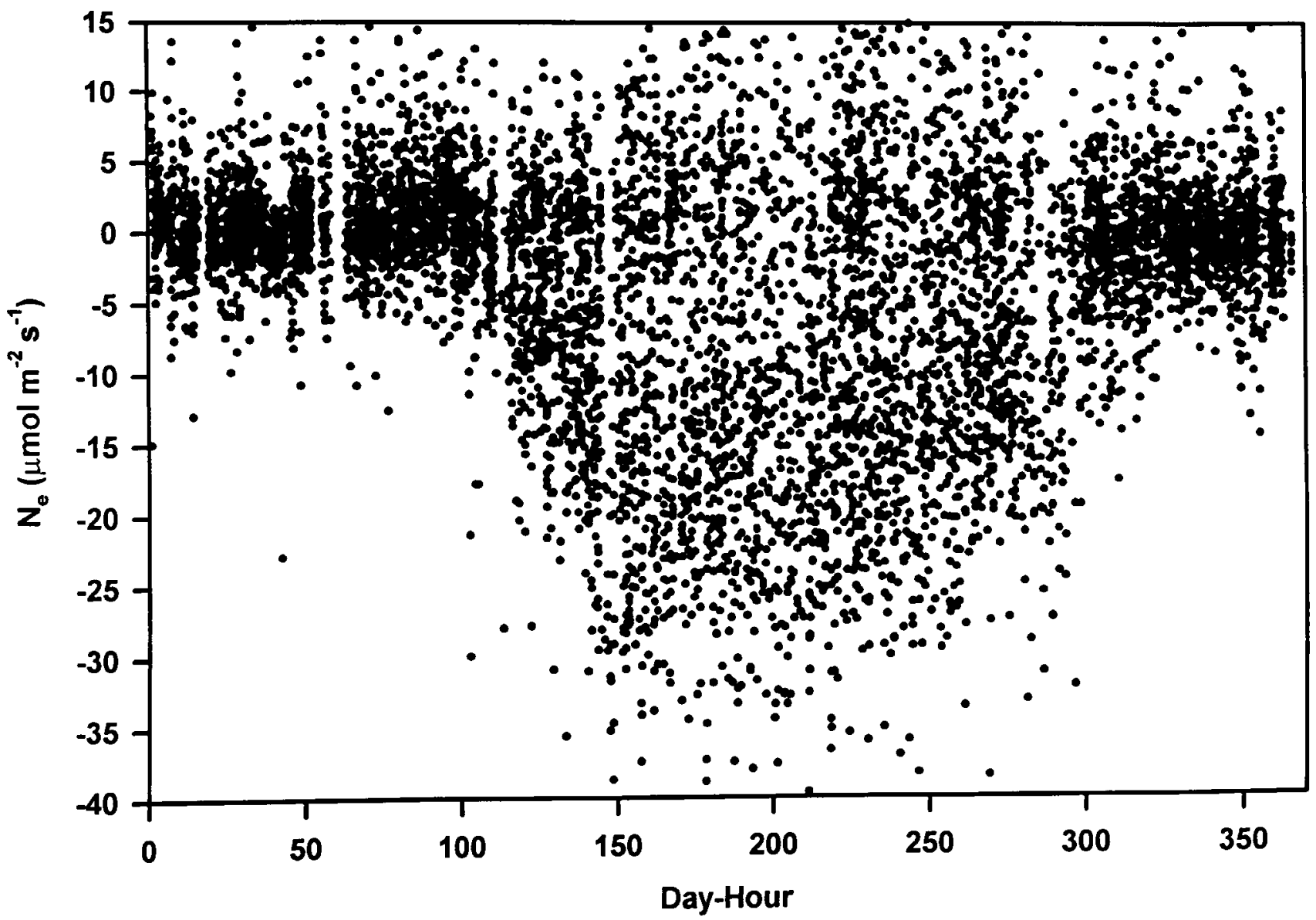

Figure 8. The seasonal pattern of net canopy $\mathrm{CO}_{2}$ exchange, as computed by the sum of the eddy covariance, storage and vertical advection terms, Equation (11). 


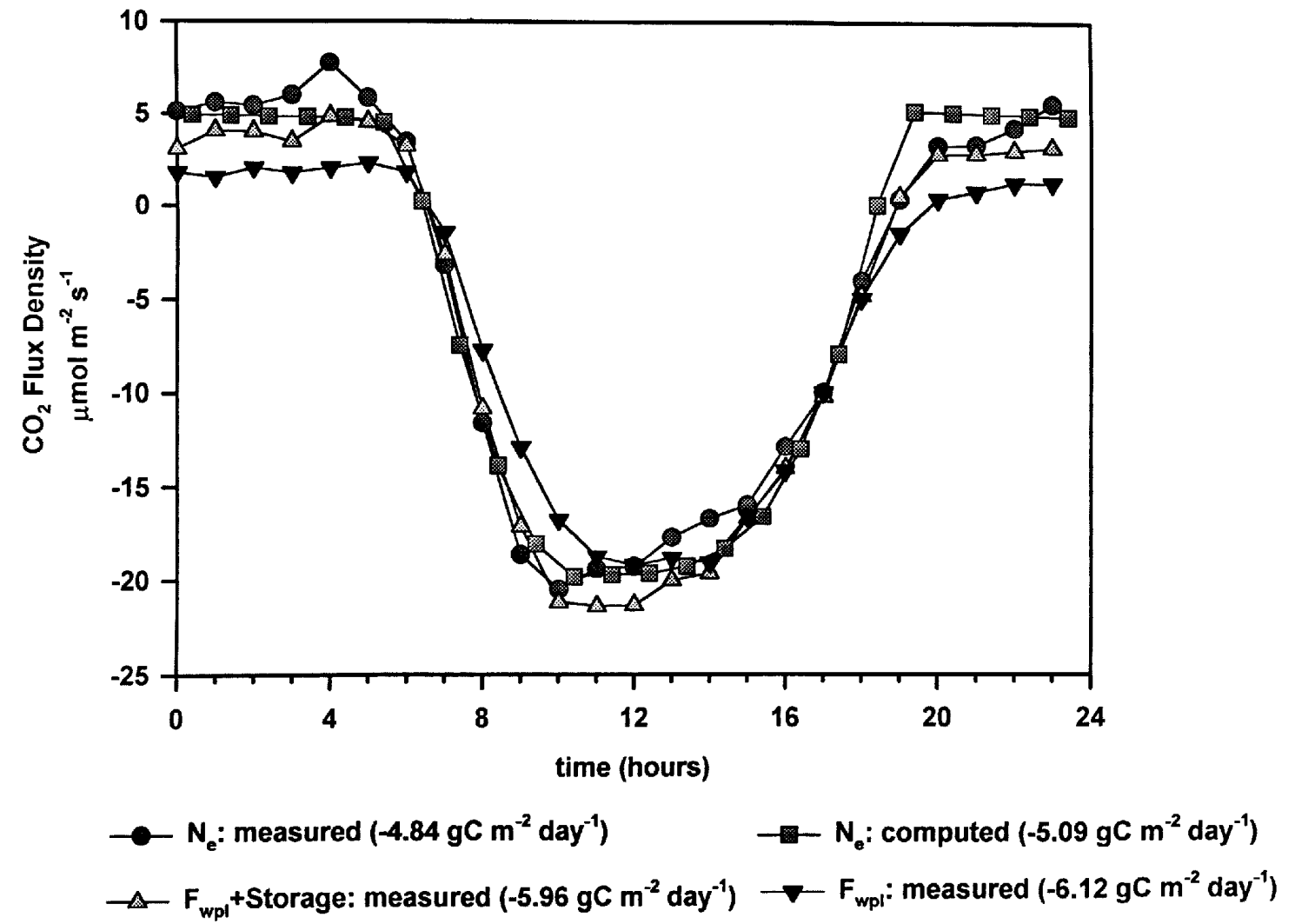

Figure 9. The diurnal pattern of mean hourly net ecosystem $\mathrm{CO}_{2}$ exchange computed four ways: (a) as a function of the $\overline{w^{\prime} c^{\prime}}$ covariance (Equation (3)); (b) as a function of the $\overline{w^{\prime} c^{\prime}}$ covariance, plus the storage term (Equation (4)); (c) as a function of the $\overline{w^{\prime} c^{\prime}}$ covariance, plus the storage term and advection term (Equation (11)); (d) calculations based on the CANOAK model. These data were bin-averaged by hour and are from the growing season (Days 150 to 250). 
accurate nocturnal calculations of respiration. The model also predicts water and energy flux density measurements well. Third, the photosynthesis and respiration components of the CANOAK model were parameterized with information from our field site, so its calculations are constrained by local data (Hanson et al., 1993; Harley and Baldocchi, 1995; Wilson et al., 2000). As for night periods, we are inclined to trust the model as a standard, as eddy covariance readings of near zero are not defensible. Canopy respiration should scale as the sum of soil respiration and the product of leaf area index and leaf respiration (Lavigne et al., 1997). Based on this principle, nighttime, growing season, canopy efflux values should exceed $5 \mu \mathrm{mol} \mathrm{m}{ }^{-2} \mathrm{~s}^{-1}$.

The mean diurnal patterns of the advection and storage terms, representative of the growing season, are very prominent (Figure 10). During dark periods, both terms are positive, representing a loss of carbon from the biosphere and a gain by the atmosphere. In the morning, the storage term exhibits a transition from storing to losing $\mathrm{CO}_{2}$. Furthermore, this transition occurs about two hours before the advection term changes from importing to exporting material in and out of the vertical volume of air under study. During midday, the advection term oscillates about zero, while the storage term decreases towards zero after midmorning. When summed over a day, the storage term is nearly zero, $0.18 \mathrm{~g} \mathrm{C} \mathrm{m}^{-2} \mathrm{day}^{-1}$. In contrast, the daily integral of the advection term is $1.19 \mathrm{~g} \mathrm{C} \mathrm{m}^{-2}$ day $^{-1}$.

A different set of inter-relationships occurs between measured and calculated values of $N_{e}$ during the dormant period (Figure 11). Here, we compare estimates of $N_{e}$ based on Equations (4) and (11), the CANOAK model and measurements made at the forest floor with an eddy covariance measurement system. The CANOAK model predicts that $N_{e}$ is constant and positive across the day since the major driver, soil and air temperature, is nearly constant. All three measures of net carbon exchange, on the other hand, show a strong and parabolic diurnal pattern. Only around midday do measurements and model calculations match. Summed over the course of the day the model predicts that $1.75 \mathrm{~g} \mathrm{C} \mathrm{m}^{-2}$ day $^{-1}$ are lost from the forest system. In comparison, the forest floor system measures $0.73 \mathrm{~g} \mathrm{C} \mathrm{m}^{-2}$ day $^{-1}$ and the tower measures $0.34 \mathrm{~g} \mathrm{C} \mathrm{m}^{-2} \mathrm{day}^{-1}$. These measurements imply horizontal advection is removing approximately half of the carbon dioxide flux between 2 and $37 \mathrm{~m}$, ignoring storage, which should sum to zero over 24 hours. Therefore, the model calculations and these data suggest that $\mathrm{CO}_{2}$ is advecting ('leaking') out the side of the control volume under the tower and is not crossing the plane where the eddy covariance instrumentation is located.

During the dormant period, the canopy storage and vertical advection terms are small ( $\pm 1 \mu \mathrm{mol} \mathrm{m}^{-2} \mathrm{~s}^{-1}$; Figure 12) because the gradients of $\mathrm{CO}_{2}$ between the forest floor and tower top are small. So inclusion of these two terms does not remedy wintertime $\mathrm{CO}_{2}$ effluxes as well as during the growing season. The impact of vertical advection and storage on the interpretation of the below canopy eddy fluxes is also expected to be small since the $\mathrm{CO}_{2}$ storage in the thin layer is small and the mean advective vertical velocity approaches zero at the ground. 


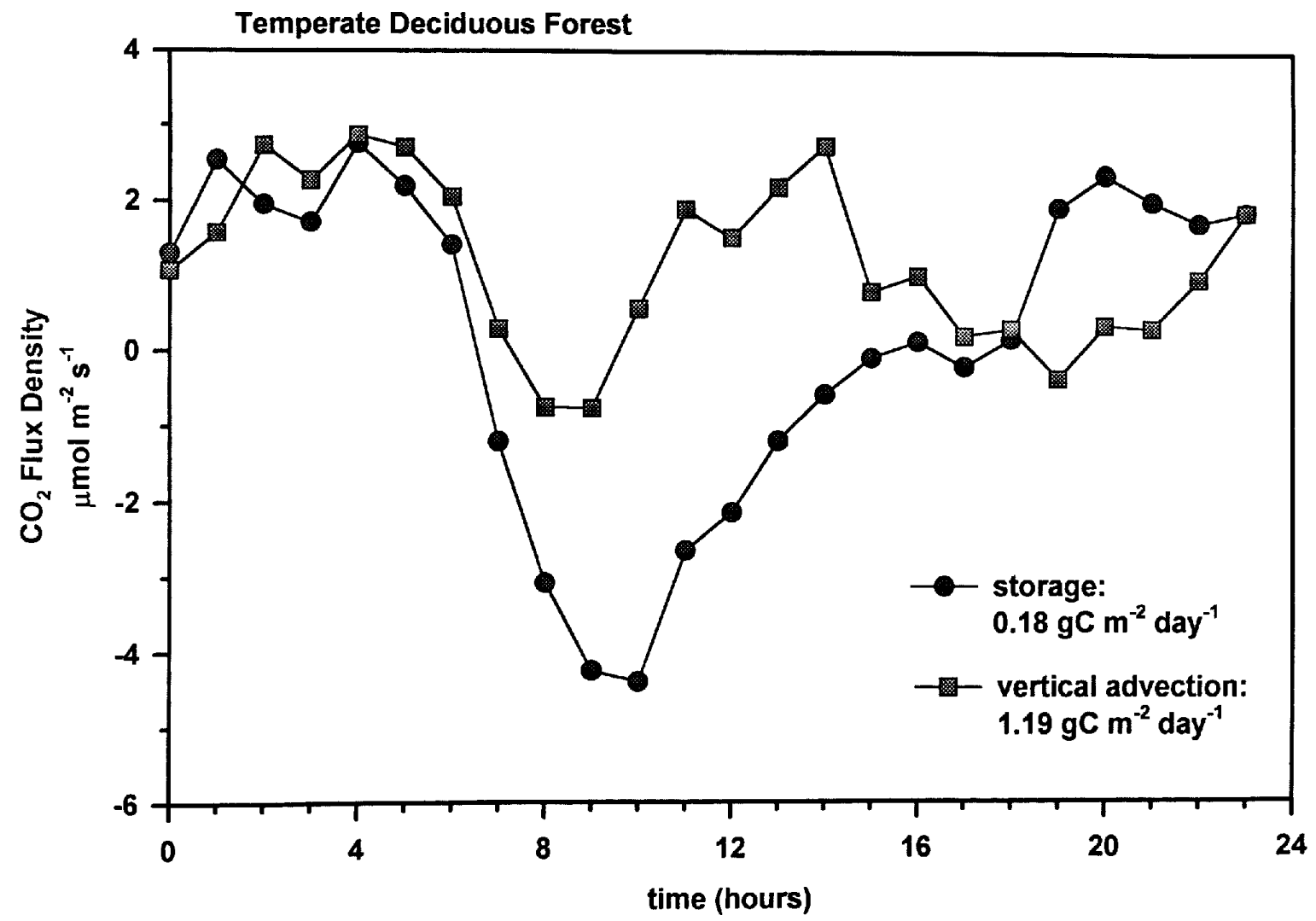

Figure 10. The diurnal pattern of the advection correction term and the storage correction term. These data are derived by binning data hour by hour from the growing season (Days 150 to 250 ). 


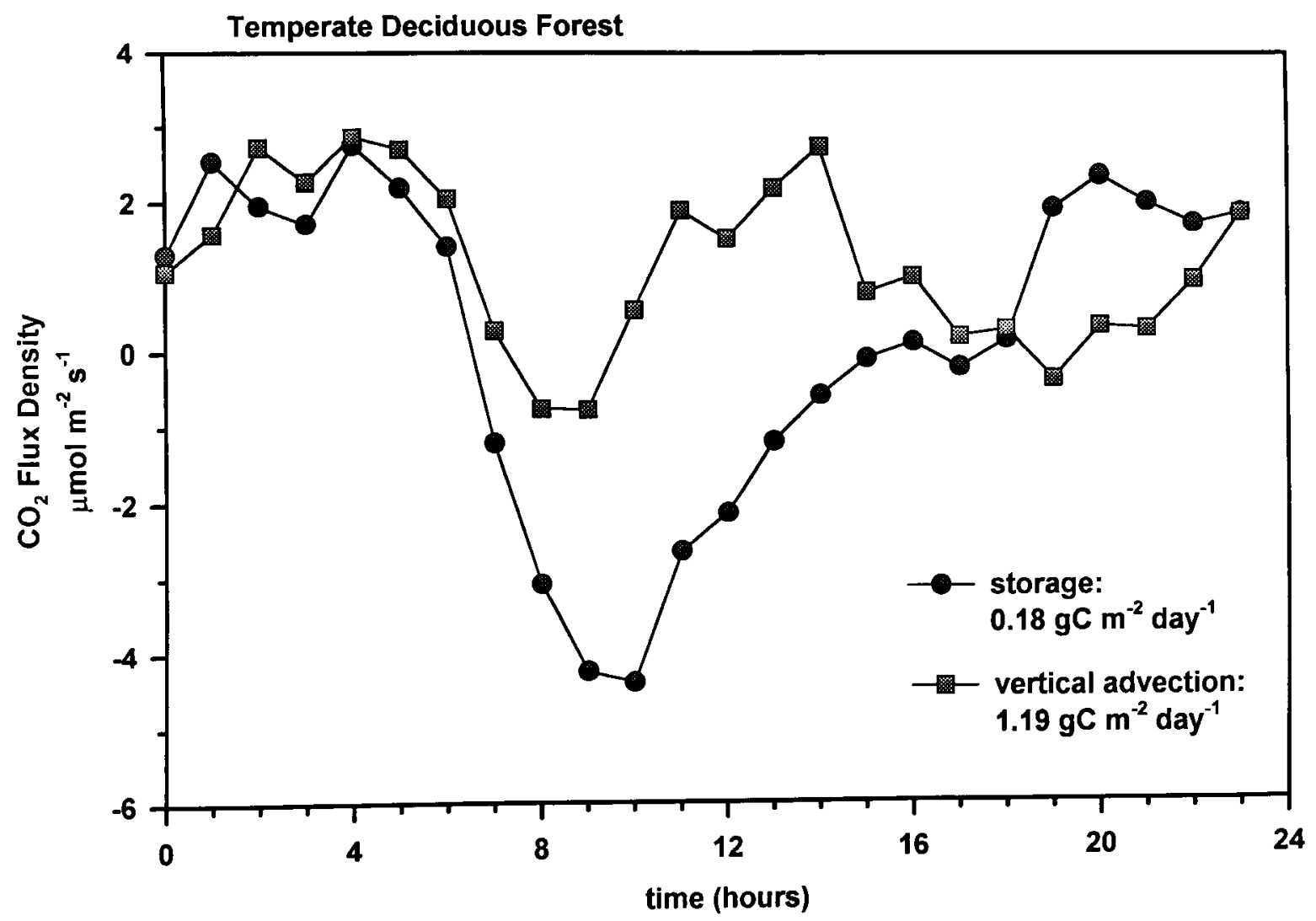

Figure 11. The diurnal pattern of hourly net ecosystem $\mathrm{CO}_{2}$ exchange computed four ways: (a) as a function of the $\overline{w^{\prime} c^{\prime}}$ covariance (Equation (3)); (b) as a function of the $\overline{w^{\prime} c^{\prime}}$ covariance, measured $2 \mathrm{~m}$ above the forest floor; (c) as a function of the $\overline{w^{\prime} c^{\prime}}$ covariance, plus the storage term and advection term (Equation (11)); (d) calculations based on the CANOAK model. These data are from the leafless dormant period. 


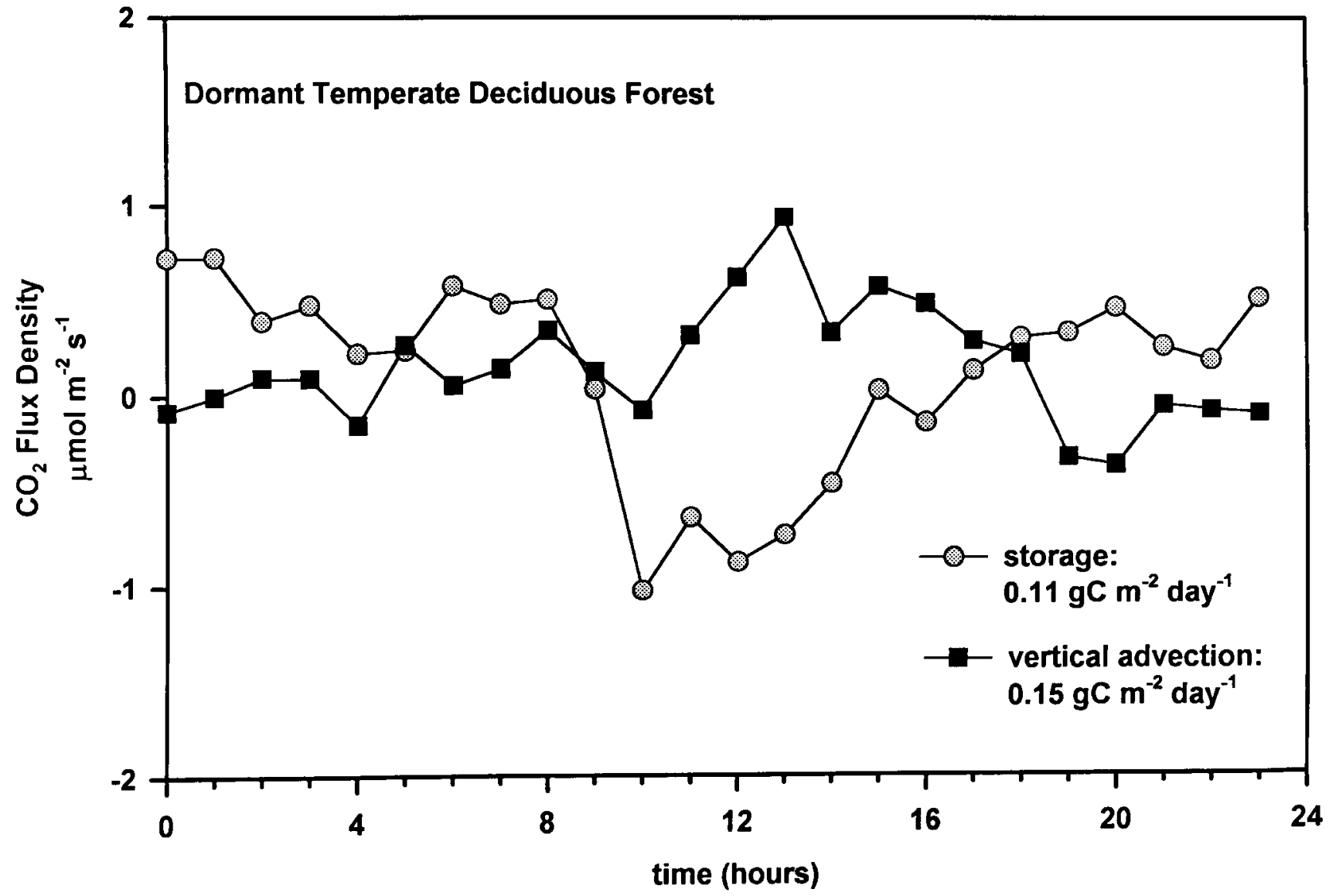

Figure 12. The diurnal pattern of the vertical advection correction term and the storage correction term. These data are derived by binning data hour by hour from the dormant season (days 1-90 and days 310-365). 
TABLE I

The annual sums of measured values were constructed by a combination of field measurements and synthetic data, which was used to fill gaps during periods when the sensors were wet, out of range or conditions did not comply with limits set by turbulence similarity theory. The gap filling routines were derived from the empirical field measurements and considered the effects of light, temperature and time of year. About $50 \%$ of the data record was corrected. The growing season was assumed to range between days 90 and 310 .

\begin{tabular}{lccc}
\hline & $\begin{array}{l}\text { Eddy covariance }+ \\
\text { storage }^{1}\end{array}$ & $\begin{array}{l}\text { Eddy covariance }+ \\
\text { storage + advection }\end{array}$ & CANOAK model \\
\hline$N_{e}\left(\mathrm{~g} \mathrm{C} \mathrm{m}^{-2}\right.$ year $\left.^{-1}\right)$ & -837 & -660 & -585 \\
$N_{e}$, growing season, day & -1067 & -974 & -1210 \\
$N_{e}$, growing season, night & 206 & 285 & 381 \\
$N_{e}$, dormant season, day & -12 & 0.5 & 117 \\
$N_{e}$, dormant season, night & 36 & 27.5 & 126 \\
\hline
\end{tabular}

The absolute differences between the measured and computed carbon effluxes, though rather small (on the order of $1 \mu \mathrm{mol} \mathrm{m}^{-2} \mathrm{~s}^{-1}$ ), are very consequential with respect to annual carbon budgets. Table I shows than annual sums of $N_{e}$ can range between -844 and $-662 \mathrm{~g} \mathrm{C} \mathrm{m}^{-2}$ year $^{-1}$, whether one uses Equations (3), (4) or (11). In comparison, $N_{e}$ based on the CANOAK model is $-585 \mathrm{~g} \mathrm{C} \mathrm{m}^{-2}$ year $^{-1}$, a value that is most closely approximated by Equation (11).

\section{Discussion}

Though Lee's advection correction (Equation (11)) improves upon our interpretation of $N_{e}$, as compared to a process based model, we cannot conclude that it is the definitive correction term for interpreting eddy covariance measurements over tall forests on complex terrain. Spatial variation in the mean flow and the scalar mixing ratio field, as a result of topography and changes in surface roughness and biospheric source and sink strengths, produce spatial variation in the mean turbulent fluxes that may not be accommodated by this one-dimensional relation.

With regard to flow over a low hill, there are four mechanisms that can induce advective fluxes of scalars, such as $\mathrm{CO}_{2}$ and water vapour (Raupach and Finnigan, 1997). One, horizontal gradients in carbon dioxide source-sink strengths will be generated along the direction of the wind passage by spatial variations in light, soil moisture, soil texture, leaf area and species composition. The radiant energy flux density to the soil and canopy is a function of the angle between the solar beam and the normal to an inclined surface. Radiation gradients along a hill impose direct spatial gradients on the surface energy balance, stomatal conductance, photosynthesis and respiration. Differential radiation interception along a hill can also 
generate streamwise differences in thermal stratification and atmospheric stability. On the longer term (season to years), the soil texture will vary from the top to the bottom of a hill, as will vegetation water use. This combination of interactions will affect the stature of vegetation, its physiological functioning and species composition.

Two, any change in surface roughness along the longitudinal axis of a hill will alter the surface stress, friction velocity $\left(u_{*}\right)$ and the eddy exchange coefficient $\left(K_{x}\right)$. This alteration, in turn, feeds the scalar flux boundary condition, as it is proportional to the product of the local eddy exchange coefficient and the scalar mixing ratio gradient, normal to the hill.

Three, as spatial variations in the turbulent stresses develop, in response to changes in the mean windfield, they will generate spatial variation in the eddy fluxes of the scalar. This can be illustrated by considering the production terms of the relevant eddy flux rate equations. These terms typically take the form of the product of turbulent stresses and mean concentration gradients, $\overline{u_{i}^{\prime} u_{j}^{\prime}} \partial \bar{c} / \partial x_{j}$ (Kaimal and Finnigan, 1994).

Four, changes in the mean scalar concentration field develop as lines of equal concentration (which were parallel to the ground in the one-dimensional case) are convected along the converging and diverging streamlines of the two-dimensional flowfield. This two-dimensional structure in mean concentration also feeds into the production terms of the eddy flux rate equations, which were noted in situation three.

Above the canopy, in steady flow conditions, changes in the eddy flux divergence, caused by the identified mechanisms, must be balanced by the advective flux divergence (e.g., Bink, 1996),

$$
\overline{\rho_{a}}\left[\bar{u} \frac{\partial \bar{c}}{\partial x}+\bar{w} \frac{\partial \bar{c}}{\partial z}\right]=-\overline{\rho_{a}}\left[\frac{\partial \overline{w^{\prime} c^{\prime}}}{\partial z}+\frac{\partial \overline{u^{\prime} c^{\prime}}}{\partial x}\right] .
$$

Lee (1998) argued, on scaling grounds, that the horizontal advection term $\bar{u} \partial \bar{c} / \partial x$ can be neglected relative to the vertical term, $\bar{w} \partial \bar{c} / \partial z$ and the horizontal component of eddy flux divergence neglected relative to the vertical, $\partial \overline{w^{\prime} c^{\prime}} / \partial z \gg \partial \overline{u^{\prime} c^{\prime}} / \partial x$. This argument is presumed to hold, in two-dimensional flowfields, when the horizontal scale of the flow is much greater than the measuring height $z_{r}$ (as in synoptic weather systems). The second of these assumptions $\left(\partial \overline{w^{\prime} c^{\prime}} / \partial z \gg \partial \overline{u^{\prime} c^{\prime}} / \partial x\right)$ is impossible to assess precisely without measurements or a model of the flow and concentration field in any particular circumstance. But it seems likely to be satisfied in many cases. The small perturbation model of Raupach et al. (1992) for flow over a low hill makes this assumption on consistent scaling grounds.

To first order, it is possible to deduce whether or not advection is significant at a given site by measuring flux divergence directly (Bink, 1996). Eddy covariance measurements were made at multiple heights above the deciduous forest to examine how big the turbulence flux divergence term could be. Our data suggest that the 
turbulent flux divergence of $\overline{w^{\prime} u^{\prime}}$ and $\overline{w^{\prime} T^{\prime}}$ were close to zero over a $7-\mathrm{m}$ distance (Figure 13). Though the terrain is complex at our site, winds tend to run along the ridge, causing the streamline deformation and flux divergence of momentum and heat transfer to be relatively small. While we may be able to conclude that at a point

$$
\overline{\rho_{a}}\left[\bar{u} \frac{\partial \bar{c}}{\partial x}+\bar{w} \frac{\partial \bar{c}}{\partial z}\right] \approx 0,
$$

neglecting $\bar{u} \partial \bar{c} / \partial x$ over $\bar{w} \partial \bar{c} / \partial z$ has less or no justification, except in special circumstances. We can see this by considering two typical flow fields.

\subsection{TOPOGRAPHICALLY AND DiABATICALLY FORCED FLOWS WITH A BACKGROUND WIND.}

Topographically and diabatically forced flows possess a background wind and wind motion that is associated with the passage of convective cells of the planetary boundary layer. The two advection terms involve products of the total velocity field, which now consists of the background plus perturbation, and the total concentration gradient. The concentration gradient responds to the changes in eddy flux and to advection by the disturbed windfield in a complex way. We listed earlier the various contributions to these changes. To decide how the two components of advective flux divergence are related at an arbitrary measurement point, we require measurements or a model of the particular flow field in question. We can investigate the question conceptually by enlisting the model of Raupach et al. (1992) of scalar flux and concentration over a low hill. This model can represent the effect of a small perturbation caused by a hill or a weak manifestation of the diabatic effects we have already mentioned.

The model is linear and can be written from the conservation equation as

$$
\rho_{a}\left[\overline{u_{0}} \frac{\partial \overline{c_{1}}}{\partial x}+\overline{w_{1}} \frac{\partial \overline{c_{0}}}{\partial z}\right]=-\rho_{a}\left[\frac{\partial \overline{w^{\prime} c^{\prime}}}{\partial z}\right]+S_{B}(x, z, t),
$$

where subscript 0 denotes the undisturbed upwind variable and subscript 1 the perturbation caused by the hill.

A fundamental feature of the linear model is the division of the flow domain into two parts. An inner region of depth $l$ exists close to the surface, where both mean momentum and scalar fields are strongly affected by perturbations to the turbulent fluxes. The outer region contains mean air flow that responds inviscidly to the hill. Changes to the scalar field are caused entirely by advection along the distorted mean flow streamlines. At our field site the depth of the inner region is estimated to be between 25 and $35 \mathrm{~m}$ above the surface.

Considering the horizontal advection term first, the linear theory computes $\overline{c_{1}}$, the perturbation to the concentration field, as the sum of four components. 

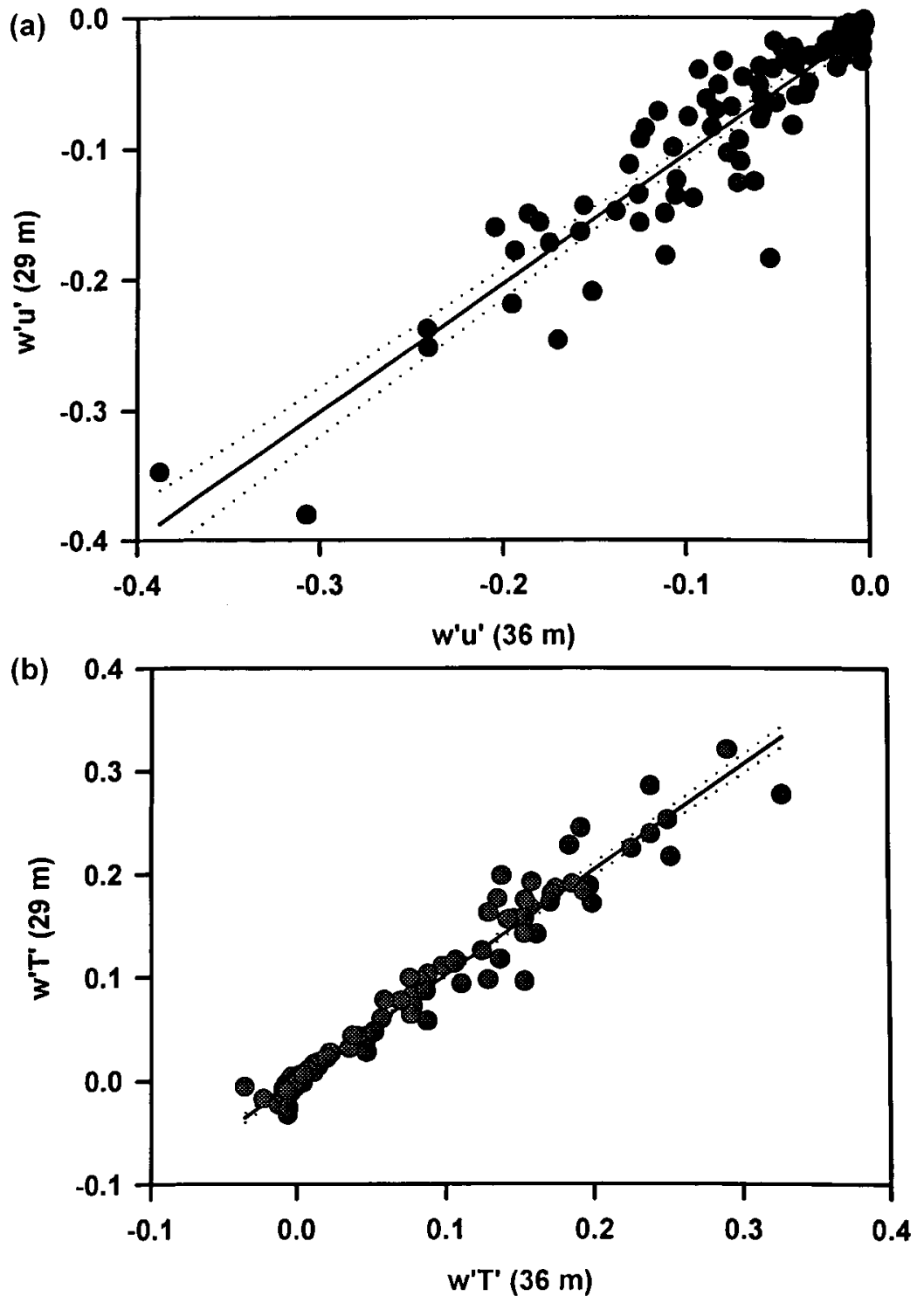

Figure 13. Comparison between turbulent eddy fluxes at two heights within the surface boundary layer of a $26 \mathrm{~m}$ tall, temperate broadleaf forest. The lowest level was at $29 \mathrm{~m}$ and the highest level was at $36 \mathrm{~m}$. (a) Momentum shear stress $\left(\overline{\left.w^{\prime} u^{\prime}\right)}, 0.981\right.$, zero-intercept: $-0.0068, r^{2}: 0.867$. (b) The covariance between vertical velocity and temperature fluctuations, slope: 1.014, zero-intercept: $0.0002, r^{2}: 0.962$. 
Each component is the result of one of the four mechanisms we listed earlier as contributing to the change in eddy flux. These component are: streamline convergence/divergence, changes in turbulent stresses, changes in surface shear stress and changes in surface scalar flux.

As we traverse the hill, contributions to $\overline{c_{1}}$ from the first three components vary in phase with each other. Below $z=l$ the effect of surface shear stress dominates, theoretically. The influences on $\overline{c_{1}}$ of stress changes and streamline convergence/divergence are smaller in magnitude and opposing each other.

Above $z=l$, only the streamline convergence/divergence effect can be significant. The fourth contribution to $\overline{c_{1}}$, that from changes in surface scalar flux, depends entirely upon how this changes as we pass over the hill. It need not be in phase with the other contributions to $\overline{c_{1}}$. For evaporation and sensible heat, it will respond to the interaction of slope angle and sun elevation and to the difference of water availability between hilltop and valley.

Moving to the vertical advection term, $\overline{w_{1}} \partial \overline{c_{0}} / \partial z$, linearized theory shows that over the hill, $\overline{w_{1}}$ varies in phase with the first three contributions to $\overline{u_{0}} \partial \overline{c_{1}} / \partial x$. Furthermore, within the assumptions of linearity, contributions to $\overline{u_{0}} \partial \overline{c_{1}} / \partial x$ from changes in turbulent stresses and changes in surface shear stress do not depend directly on the sign of $\partial \overline{c_{0}} / \partial z$. A change of the sign of the background scalar gradient, as occurs for example during the twice-daily switch between assimilation and respiration dominance of the $\mathrm{CO}_{2}$ flux, can reverse the sign of the vertical advection term in the inner layer with only a small effect on the horizontal one.

With these results, we are in a position to compare the relative signs and magnitudes of the two advection terms. Above the inner layer, where only the effect of streamline convergence/divergence affects the scalar perturbation, the theory yields the simple result that the two advection terms are of opposite sign and approximately equal magnitude. In the inner layer where most of our measurements are made, the sign of the horizontal advection term $\overline{u_{0}} \partial \overline{c_{1}} / \partial x$ is determined by the relative strengths of the four competing influences on $\overline{c_{1}}$ although with uniform surface roughness and constant surface scalar flux it will have the same sign as the contribution from streamline convergence/divergence but be larger in magnitude (Raupach et al., 1992). In the inner layer, the sign and magnitude of the vertical advection term is set by the background scalar gradient in a way that is essentially independent of the dominant contributions to the horizontal term.

In summary, according to this simple linear model, the two contributions to advection are almost equal and opposite in regions of the flow where changes in turbulent flux divergence are small. Within the inner layer, where most measurements are made, the two terms may be of considerably different magnitude and of the same or opposite sign, depending on the relative contributions of the various competing influences on $\overline{c_{1}}$. Clearly, when there is a large-scale background flow, we have no grounds for using a measurement of $\bar{w} \partial \bar{c} / \partial z$ as a bound on total advection at an arbitrary point in the flow and in the outer layer its inclusion will 
make budget closure worse as in reality it would be cancelled by the horizontal term.

Data in Figure 14 provide indirect evidence that the advection term, $\bar{u} \partial \bar{c} / \partial x$, is non-zero. During the growing season, $\mathrm{CO}_{2}$ concentration measured $36 \mathrm{~m}$ above the ground varies between about 360 and $450 \mathrm{ppm}$ over the course of a day in a regular and repeatable manner. Temporal variations in $\mathrm{CO}_{2}$ near the forest floor, in contrast, are highly irregular. They can increase and decrease by $100 \mathrm{ppm}$ within a few hours, without any related change occurring at the top of the column. This decoupling between $\mathrm{CO}_{2}$ measured near the forest floor and the top of the tower suggests that $\mathrm{CO}_{2}$ is advecting in and out of the horizontal sides of the air column. In other words, $\mathrm{CO}_{2}$ moving past the forest floor system is leaking out the sides of the vertical air column before it can cross the horizontal plain above the forest.

During the winter dormant period, the differences between $\mathrm{CO}_{2}$ measured at 36 and $2 \mathrm{~m}$ are small and temporal variations are well correlated at the two heights (Figure 15). Closer inspection of these data, however, reveals that many periods occur when $\mathrm{CO}_{2}$ concentration at 36 m exceeds measurements near the forests floor. This gradient is counter to what one would expect from a supposedly respiring forest. These results indicate either plume impaction, boundary-layer entrainment of elevated $\mathrm{CO}_{2}$ or the near surface drainage of $\mathrm{CO}_{2}$ down the hill.

\subsection{Slow PASSAGE OF CONVECTIVE CELLS OF THE PLANETARY BOUNDARY LAYER}

If the horizontal velocity of the convection cells is small compared to the convective velocity scale $w_{*}$, then regions of updraft and downdraft will be located randomly over the tower for time periods long compared with the timescale of the dominant turbulent motion at tower height (where $w_{*}=\left[g \frac{\overline{w^{\prime} \theta^{\prime} z_{i}}}{T_{0}}\right]^{1 / 3}, g$ is the acceleration due to gravity, $T_{0}$ the reference temperature, $\overline{w^{\prime} \theta^{\prime}}$ the turbulent heat flux and $z_{i}$ the convective boundary-layer depth). As pointed out by Lee (1998), the likelihood of being in a downdraft is greater than that of being in an updraft but updrafts are stronger than downdrafts. The horizontal velocities generated near the surface by such motions will be of order $w_{*}$ and the distance between updraft and downdraft regions will be, on average, $z_{i}$. It is possible that in such situations the neglected horizontal contributions to advection will cancel out on average and that recording the vertical advection term in the budget in the form of Equation (11) will improve closure but this supposition remains to be tested more thoroughly.

We can summarize the conclusions of this section by saying that in general, twoand three-dimensional flowfields require $2 \mathrm{D}$ or $3 \mathrm{D}$ analysis frameworks. Only in the case of a tower located at or near a stagnation streamline of an anabatic or katabatic flow can we expect to improve budget closure by adding the vertical advection term, the only component of advection available from a single tower. In more general flows containing a large-scale background wind, the relationship between vertical and horizontal advection terms is controlled by a set of competing 


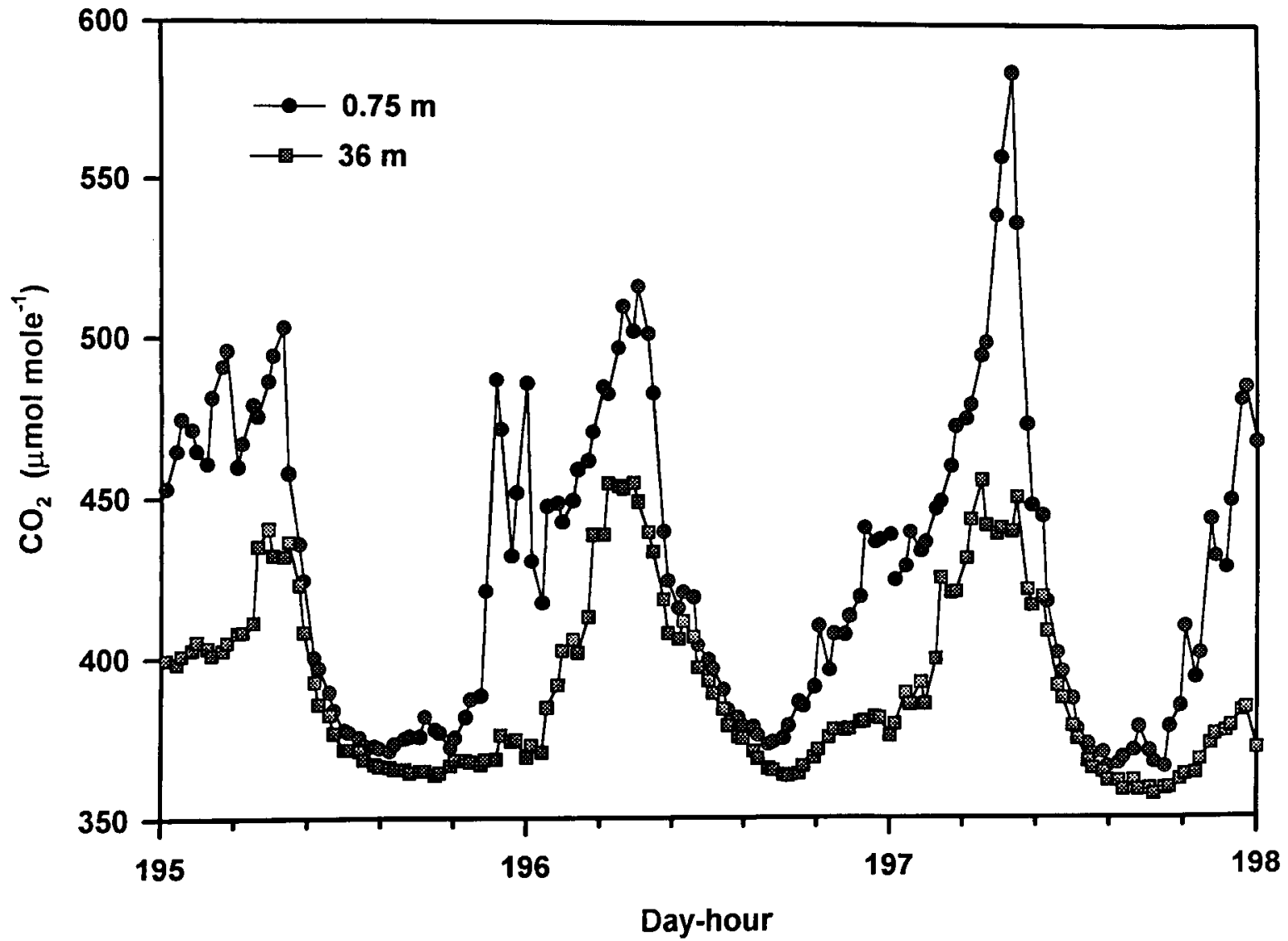

Figure 14. $\mathrm{CO}_{2}$ measurements near the forest floor $(0.75 \mathrm{~m})$ and above the forest $(36.6 \mathrm{~m})$ for days 195 to 198,1997 


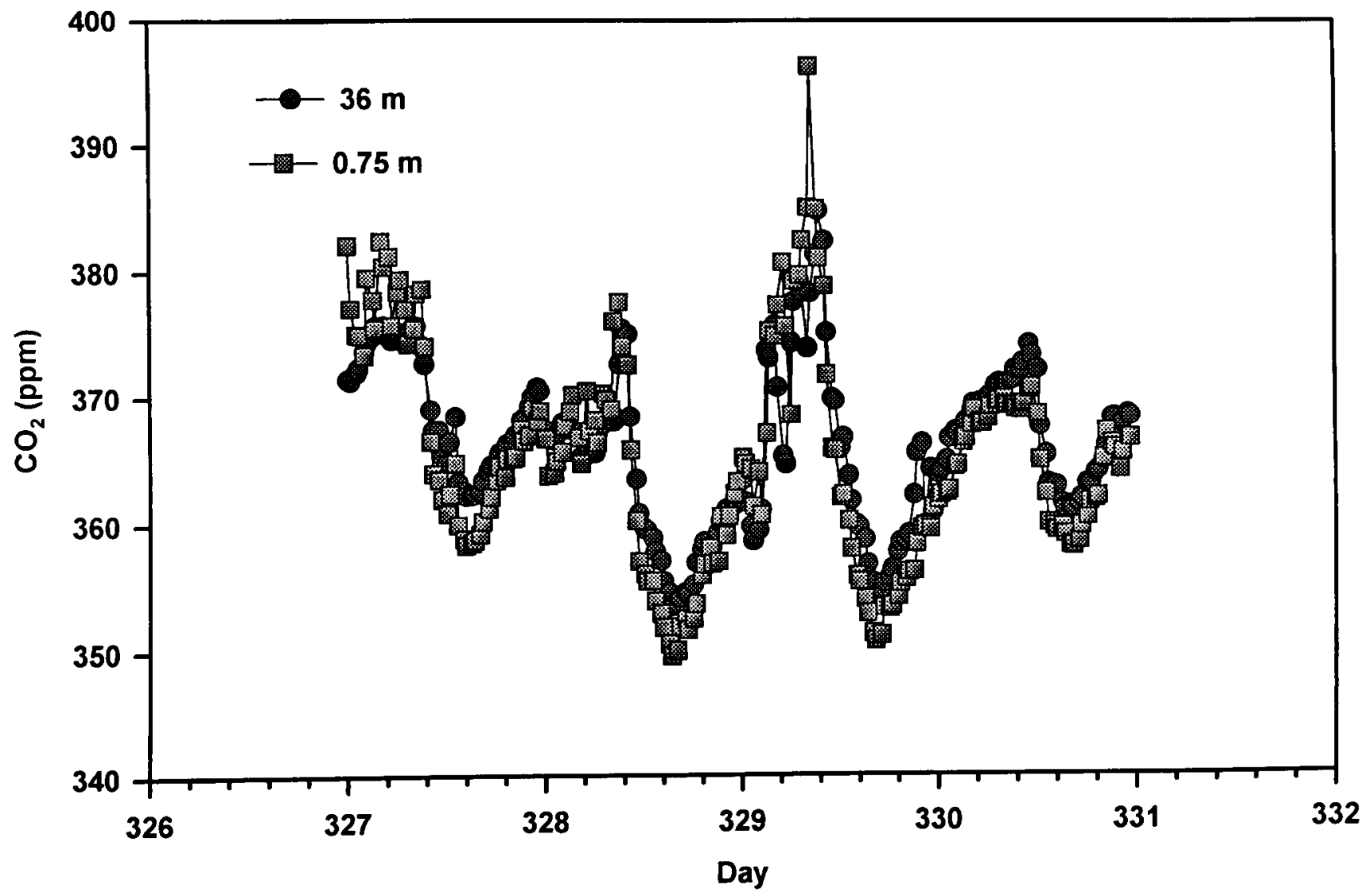

Figure 15. $\mathrm{CO}_{2}$ measurements near the forest floor $(0.75 \mathrm{~m})$ and above the forest $(36.6 \mathrm{~m})$ for days 326 to $332,1997$. 
influences and universal predictions about their relative sizes or even their relative signs can only be made in regions of the flow where perturbations to the eddy flux are negligible. In such circumstances, Equation (11) may be an incomplete representation of mass conservation.

\section{Conclusions}

We have investigated the applicability of Lee's advection correction term for measuring long term $\mathrm{CO}_{2}$ exchange over a forest on complex terrain. Inclusion of the vertical advection term yields hourly, daily and annual sums of net ecosystem $\mathrm{CO}_{2}$ exchange that are more ecologically correct, during the growing season. During the winter dormant period, nighttime detected rates of an actively respiring forest are near zero. Only during midday do model calculations and measurements of $N_{e}$ match. On an annual basis, sums of $N_{e}$ without the advection correction were $40 \%$ too large, as compared with model computations. We cannot conclude that the Lee correction term is definitive for evaluating $\mathrm{CO}_{2}$ exchange over tall forests in complex terrain. There is an indication that the neglected term, $\bar{u} \partial \bar{c} / \partial x$, is nonzero and that $\mathrm{CO}_{2}$ is leaking out of the sides of control volume (within the forest) during the winter.

There are also practical problems with applying the Lee correction to longterm $\mathrm{CO}_{2}$ flux density data bases. The inclusion of additional terms compounds measurement errors and increases the probability of instrument malfunction.

\section{Acknowledgements}

This work is supported by the U.S. Department of Energy's Terrestrial Carbon Program and this work contributes to the AmeriFlux program. We thank Mark Hall, Mark Brewer, David Auble and Detlef Matt from NOAA/ATDD for their assistance in the acquisition of the field data. We thank Paul Hanson of Oak Ridge National Lab for supplying leaf area index measurements. Internal reviews of an earlier version of this document were graciously provided by Xuhui Lee, Mike Unsworth, Niels Otto Jenson and Marc Fischer.

One of us (KTPU), was supported by grants from the U.S. Department of Energy (DOE) National Institute for Global Environmental Change (NIGEC) through the NIGEC Western Regional Center at the University of California Davis (DOE Cooperative Agreement No. DE-FCO3-90ER61010) 


\section{References}

Aubinet, M., Grelle, A., Ibrom, A., Rannik, U., Moncrieff, J., Foken, T., Kowalski, P., Martin, P., Berbigier, P., Bernhofer, Ch., Clement, R., Elbers, J., Granier, A., Grunwald, T., Morgenster, K., Pilegaard, K., Rebmann, C., Snijders, W., Valentini, R., and Vesala, T.: 2000, 'Estimates of the Annual Net Carbon and Water Exchange of European Forests: The EUROFLUX Methodology', Adv. Ecol. Res. 30, 113-174.

Auble, D. and Meyers, T. P.: 1992, 'An Open Path, Fast Response Infrared Absorption Gas Analyzer for $\mathrm{H}_{2} \mathrm{O}$ and $\mathrm{CO}_{2}$ ', Boundary-Layer Meteorol. 59, 243-256.

Avissar, R. and Pielke, R. A.: 1989, 'A Parameterization of Heterogeneous Land Surfaces for Atmospheric Numerical Models and its Impact on Regional Meteorology’, Mon. Wea. Rev. 117, 2113-2136.

Baldocchi, D. D.: 1997, 'Measuring and Modeling Carbon Dioxide and Water Vapor Exchange over a Temperate Broad-Leaved Forest during the 1995 Summer Drought', Plant Cell Environ. 20, 1108-1122.

Baldocchi, D. D. and Meyers, T. P.: 1991, 'Trace Gas Exchange at the Floor of a Deciduous Forest: I. Evaporation and $\mathrm{CO}_{2}$ Efflux', J. Geophys. Res. 96, 7271-7285.

Baldocchi, D. D and Meyers, T. P.: 1998, 'On Using Eco-Physiological, Micrometeorological and Biogeochemical Theory to Evaluate Carbon Dioxide, Water Vapor and Gaseous Deposition Fluxes over Vegetation', Agric. For. Meteorol. 90, 1-26.

Baldocchi, D. D., Hicks, B. B., and Meyers, T. P.: 1988, 'Measuring Biosphere-Atmosphere Exchanges of Biologically Related Gases with Micrometeorological Methods', Ecology 69, 1331-1340.

Baldocchi, D. D., Valentini, V., Running, S. R., Oechel, W., and Dahlman, R.: 1996, 'Strategies for Measuring and Modelling $\mathrm{CO}_{2}$ and Water Vapor Fluxes over Terrestrial Ecosystems', Global Change Biol. 2, 159-168.

Bink, N. J.: 1996, The Structure of the Atmospheric Surface Layer Subject to Local Advection, Ph.D. Thesis. Agricultural University, Wageningen, The Netherlands.

Black, T. A., den Hartog, G., Neumann, H., Blanken, P., Yang, P., Nesic, Z., Chen, S., Russel, C., Voroney, P., and Staebler, R.: 1996, 'Annual Cycles of $\mathrm{CO}_{2}$ and Water Vapor Fluxes above and within a Boreal Aspen Stand', Global Change Biol. 2, 219-230.

Canadell, J., Mooney, H., Baldocchi, D.,. Berry, J., Ehleringer, J., Field, C., Gower, T., Hollinger, D., Hunt, J., Jackson, R., Running, S., Shaver, G., Trumbore, S., Valentini, R., and Yoder, B.: 2000, 'Carbon Metabolism of the Terrestrial Biosphere', Ecosystems, in press.

Chambers, M. L. S.: 1998, Characterization of Forest Floor Carbon Dioxide Efflux from Three Forest Ecosystems in East Tennessee, U.S.A., Masters Thesis, University of Tennessee, Knoxville, TN, $159 \mathrm{pp}$.

Chen, W. J., Black, T. A., Yang, P. C., Barr, A. G., Neumann, H. H., Nesic, Z., Blanken, P. D., Novak, M. D., Eley, J., Ketler, R. J., and Cuenca, R.: 1999. 'Effects of Climatic Variability on the Annual Carbon Sequestration by a Boreal Aspen Forest', Global Change Biol. 5, 41-54.

Edwards, N. T., Johnson, D. W., McLaughlin, S. B., and Harris, W. F.: 1989. 'Carbon Dynamics and Productivity', in J. W. Johnson and R. I. van Hook (eds.), Analysis of Biogeochemical Cycling Processes in Walker Branch Watershed, Springer-Verlag, New York, NY, pp. 197-232.

Fan, S. M., Gloor, M., Mahlman, J., Pacala, S., Sarmiento, J., Takahashi, T., and Tans, P.: 1998, 'A Large Terrestrial Carbon Sink in North America Implied by Atmospheric and Oceanic Carbon Dioxide Data and Models', Science 282, 442-446.

Foken, Th. and Wichura, B.: 1995, 'Tools for Quality Assessment of Surface-Based Flux Measurements', Agric. For. Meteorol. 78, 83-105.

Goulden, M. L., Munger, J. W., Fan, S. M. Daube, B. C., and Wofsy, S. C.: 1996a, 'Exchange of Carbon Dioxide by a Deciduous Forest: Response to Interannual Climate Variability', Science 271, 1576-1578. 
Goulden, M. L., Munger, J. W., Fan, S. M. Daube, B. C., and Wofsy, S. C. 1996b, 'Measurement of Carbon Storage by Long-Term Eddy Correlation: Methods and a Critical Assessment of Accuracy', Global Change Biol. 2, 169-182.

Goulden, M. L., Wofsy, S. C., Harden, J. W., Trumbore, S. E., Crill, P. M., Gower, S. T., Fires, T., Daube, B. C., Fan, S. M., Sutton, D. J., Bazzaz, A., and Munger, J. W.: 1998, 'Sensitivity of Boreal Forest Carbon Balance to Soil Thaw', Science 279, 214-217.

Greco, S. and Baldocchi, D. D.: 1996, 'Seasonal Variations of $\mathrm{CO}_{2}$ and Water Vapour Exchange Rates over a Temperate Deciduous Forest', Global Change Biol. 2, 183-198.

Hanson, P. J., Wullschleger, S. D., Bohlman, S. A., and Todd, D. E.: 1993. 'Seasonal and Topographic Patterns of Forest Floor $\mathrm{CO}_{2}$ Efflux from an Upland Oak Forest', Tree Physiol. 13, 1-15.

Harley, P. C. and Baldocchi, D. D.: 1995, 'Scaling Carbon Dioxide and Water Vapor Exchange from Leaf to Canopy in a Deciduous Forest: Leaf Level Parameterization', Plant Cell Environ. 18, $1146-1156$.

Heimann, M., Keeling, C. D., and Fung, I.: 1986, 'Simulating the Atmospheric Carbon Dioxide Distribution with a Three Dimensional Tracer Model', in J. R. Trabalka and D. E. Reichle (eds.), The Changing Carbon Cycle: A Global Analysis, Springer-Verlag, pp. 16-49.

Hollinger, D. Y. and Wofsy, S. C.: 1997, 'Science Plan for AmeriFlux: Long-Term Flux Measurement Network of the Americas', http://www.esd.ornl.gov/programs/NIGEC/scif.htm

Hutchison, B. A. and Baldocchi, D. D.: 1989, 'Forest Meteorology', in D. W. Johnson and R. I. Van Hook (eds.), Analysis of Biogeochemical Cycling Processes in Walker Branch Watershed, Springer-Verlag, pp. 21-95.

Jarvis, P. G., Massheder, J., Hale, S., Moncrieff, J., Rayment, M., and Scott, S.: 1997, 'Seasonal Variation of Carbon Dioxide, Water Vapor and Energy Exchanges of a Boreal Black Spruce Forest', J. Geophys. Res. 102, 28953-28967.

Kaimal, J. C. and Finnigan, J. J.: 1994, Atmospheric Boundary Layer Flows: Their Structure and Measurement, Oxford University Press, Oxford, U.K., 289 pp.

Lavigne, M. B., Ryan, M. G., Anderson, D. E., Baldocchi, D. D., Crill, P. M., Fitzjarrald, D. R., Goulden, M. L., Gower, S. T., Massheder, J. M., McCauhey, J. H., Rayment, M., and Striegl, R. G.: 1997, 'Comparing Nocturnal Eddy Covariance Measurements to Estimates of Ecosystem Respiration Made by Scaling Chamber Measurements', J. Geophys. Res. 102, 28977-28986.

Lee, X.: 1998, 'On Micrometeorological Observations of Surface-Air Exchange over Tall Vegetation', Agric. For. Meteorol. 91, 39-50.

Lee, X. H., Black, T. A., den Hartog, G., Neumann, H., Nesic, Z., and Olejnik, J.: 1996, 'Carbon Dioxide Exchange and Nocturnal Processes over a Mixed Deciduous Forest', Agric. For. Meteorol. 81, 13-29.

Lindroth, A., Grelle, A., and Moren, A. S.: 1998, 'Long-Term Measurements of Boreal Forest Carbon Balance Reveal Large Temperature Sensitivity', Global Change Biol. 4, 443-450.

McMillen, R. T. 1988. 'An Eddy Correlation Technique with Extended Applicability to Non-Simple Terrain', Boundary-Layer Meteorol. 43, 231-245.

Moncrieff, J. B., Mahli, Y., and Leuning, R.: 1996, 'The Propagation of Errors in Long Term Measurements of Land Atmosphere Fluxes of Carbon and Water', Global Change Biol. 2, 231-240.

Mordukhovich, M. I. and Tsvang, L. R.: 1966, 'Direct Measurement of Turbulent Flows at Two Heights in the Atmospheric Ground Layer', Izvestia, Atmos. Oceanic Phys. 2, 786-803.

Paw U, K. T., Baldocchi, D., Meyers, T., and Wilson, K.: 2000, 'Correction of Eddy Covariance Measurements Incorporating Both Advective Effects and Density Fluxes', Boundary-Layer Meteorol., in press.

Rannik, U.: 1998, 'On the Surface Layer Similarity at a Complex Forest Site', J. Geophys. Res. 103, 8685-8697.

Rao, K. S., Wyngaard, J. C., and Cote, O. R.: 1974, 'Local Advection of Momentum, Heat, and Moisture in Micrometeorology', Boundary-Layer Meteorol. 7, 331-348. 
Raupach, M. R. and Finnigan, J. J.: 1997, 'The Influence of Topography on Meteorological Variables and Surface-Atmosphere Interactions', J. Hydrol. 190, 182-213.

Raupach, M. R., Weng, W. S., Carruthers, D. J., and Hunt, J. C. R.: 1992, 'Temperature and Humidity Fields and Fluxes over Hills', Quart. J. Roy. Meteorol. Soc. 118, 191-225.

Sun, J., Lenschow, D. H., Mahrt, L., Crawford, D. L., Davis, K. J., Oncley, S. P., MacPherson, J. I., Wang, Q., Dobosy, R. J., and Desjardins, R. L.: 1997, 'Lake-Induced Atmospheric Circulations during BOREAS', J. Geophys. Res. 102, 29155-29166.

Tenhunen, J. D., Valentini, R., Kostner, B., Zimmermann, R., and Granier, A.: 1998, 'Variation in Forest Gas Exchange at Landscape to Continental Scales', Annales des Sciences Forestières $\mathbf{5 5}$, $1-11$.

Valentini, R. P. de Angelis, Matteucci, G., Monaco, R., Dore, S., and Scarascia-Mugnozza, G. E.: 1996, 'Seasonal Net Carbon Dioxide Exchange of a Beech Forest with the Atmosphere', Global Change Biol. 2, 199-208.

Vermetten, A. W. M., Ganzeveld, L., Jeuken, A., Hofschreuder, P., and Mohren, G. M. J.: 1994, ' $\mathrm{CO}_{2}$ Uptake by a Stand of Douglas Fir: Flux Measurements Compared with Model Calculations', Agric. For. Meteorol. 72, 57-80.

Webb, E. K., Pearman, G., and Leuning, R.: 1980, 'Correction of Flux Measurements for Density Effects Due To Heat and Water Vapor Transfer', Quart. J. Roy. Meteorol. Soc. 106, 85-100.

Wesely, M. L.: 1970, Eddy Correlation Measurements in the Atmospheric Surface Layer over Agricultural Crops, Dissertation, University of Wisconsin, Madison, WI.

Wilson, K. B., Baldocchi, D. D., and Hanson, P. J.: 2000, 'Spatial and Seasonal Variability of Photosynthesis Parameters and their Relationship to Leaf Nitrogen in a Deciduous Forest', Tree Physiol., in press.

Wofsy, S. C, Goulden, M. L.,. Munger, J. W., Fan, S. M., Bakwin, P. S., Daube, B. C., Bassow, S. L., and Bazzaz, F. A.: 1993, 'Net Exchange of $\mathrm{CO}_{2}$ in a Mid-Latitude Forest', Science 260, 1314-1317. 